\title{
Culture of iPSCs Derived Pancreatic $\beta$-Like Cells In Vitro Using Decellularized Pancreatic Scaffolds: A Preliminary Trial
}

\author{
Jian Wan, ${ }^{1,2,3}$ Yan Huang, ${ }^{1,2}$ Pengcheng Zhou, ${ }^{4}$ Yibing Guo, ${ }^{2}$ Cen Wu, ${ }^{1}$ Shajun $\mathrm{Zhu},{ }^{1}$ \\ Yao Wang, ${ }^{1}$ Lei Wang, ${ }^{1}$ Yuhua Lu, ${ }^{1,2}$ and Zhiwei Wang ${ }^{1}$ \\ ${ }^{1}$ Department of General Surgery, Affiliated Hospital of Nantong University, Nan Tong, Jiang Su, China \\ ${ }^{2}$ Research Center of Clinical Medicine, Affiliated Hospital of Nantong University, Nan Tong, Jiang Su, China \\ ${ }^{3}$ Department of General Surgery, Affiliated Cancer Hospital of Nantong University, Nan Tong, Jiang Su, China \\ ${ }^{4}$ Department of Emergency Surgery, Affiliated Hospital of Nantong University, Nan Tong, Jiang Su, China
}

Correspondence should be addressed to Yuhua Lu; lyh76@126.com and Zhiwei Wang; wzw3639@163.com

Received 31 August 2016; Revised 30 December 2016; Accepted 19 January 2017; Published 5 April 2017

Academic Editor: Costantino Del Gaudio

Copyright (C) 2017 Jian Wan et al. This is an open access article distributed under the Creative Commons Attribution License, which permits unrestricted use, distribution, and reproduction in any medium, provided the original work is properly cited.

\begin{abstract}
Diabetes mellitus is a disease which has affected 415 million patients in 2015. In an effort to replace the significant demands on transplantation and morbidity associated with transplantation, the production of $\beta$-like cells differentiated from induced pluripotent stem cells (iPSCs) was evaluated. This approach is associated with promising decellularized scaffolds with natural extracellular matrix (ECM) and ideal cubic environment that will promote cell growth in vivo. Our efforts focused on combining decellularized rat pancreatic scaffolds with mouse $\mathrm{GFP}^{+}$-iPSCs-derived pancreatic $\beta$-like cells, to evaluate whether decellularized scaffolds could facilitate the growth and function of $\beta$-like cells. $\beta$-like cells were differentiated from GFP ${ }^{+}$-iPSCs and evaluated via cultivating in the dynamic circulation perfusion device. Our results demonstrated that decellularized pancreatic scaffolds display favorable biochemical properties. Furthermore, not only could the scaffolds support the survival of $\beta$-like cells, but they also accelerated the expression of the insulin as compared to plate-based cell culture. In conclusion, these results suggest that decellularized pancreatic scaffolds could provide a suitable platform for cellular activities of $\beta$-like cells including survival and insulin secretion. This study provides preliminary support for regenerating insulin-secreting organs from the decellularized scaffolds combined with iPSCs derived $\beta$-like cells as a potential clinical application.
\end{abstract}

\section{Introduction}

According to the international diabetes foundation, by 2015, 415 million adults have suffered from diabetes worldwide, with this number expected to rise to 642 million by 2040 . Type 1 diabetes mellitus (T1DM) is characterized by an absolute lack of insulin and thus is dependent on exogenous insulin treatment. However, periodic exogenous insulin injections cannot accurately regulate blood glucose levels and, despite treatment, those affected continue to suffer ill effects $[1,2]$ such as diabetic nephropathy, neuropathy, retinopathy, and arteriosclerosis. As such, the best current practice for treating diabetes involves transplantation of the islet or pancreas [3-5], but the large numbers of patients, limited supply of donor tissue, the risk and cost of operation, and necessity for lifelong immunosuppression have limited the application of this treatment modality. $\beta$-like cells differentiated from embryonic stem cells (ES) [6], induced pluripotent stem cells (iPSCs) [7], and mesenchymal stem cells (MSC) [8] have become the most promising solution by providing a potentially inexhaustible means of generating $\beta$ cells for transplantation and with low immunogenicity. Recently, Alipio et al. successfully induced iPSCs to differentiate into $\beta$-like cells [9]. Most notably, their results demonstrated amelioration of the hyperglycemic phenotype within the mouse models.

However, recent studies have shown that implanted $\beta$ like cells cannot adapt to the environment and can be easily removed by instant blood-mediated inflammatory reaction (IBMIR) [10]. While some biomaterial scaffolds have been explored to promote $\beta$-like cells engraftment and survival, none of them can factually simulate the natural growth in 
vivo due to the lack of vasculature for delivery of oxygen, nutrients, and removal of metabolite. As such, it remains essential to identify ideal extracellular microenvironment for $\beta$-like cells to survive and work effectively. Thanks to the cutting-edge technology of three-dimensional decellularized bioscaffold, there exists the possibility of creating an ideal microenvironment that is suitable for cell engraftment and which could be used to reconstruct a new functional organ. In recent years, the whole organ decellularized scaffolds for the heart [11, 12], lungs [13], liver [14, 15], kidney [16], and pancreas [17] have been developed. In brief, the natural extracellular matrix and the release of growth factors contained in biological scaffold materials provide incomparable advantages, such as promoting cell adhesion and growth. Secondly, the natural vasculature of decellularized scaffolds permits continuous nutrition perfusion and enhances vascularization. Our previous studies have demonstrated that decellularized liver scaffolds could maintain the growth and function of isolated islets and islets-like clusters [18, 19]. Considering the growth factors secreted by specific ECM should be more suitable for the growth of original cells. We hypothesized the pancreatic structure should be a better platform for pancreatic $\beta$-like cells. We attempted to cultivate mouse $\mathrm{GFP}^{+}$-iPSCs derived pancreatic $\beta$-like cells using a decellularized rat pancreatic scaffold.

In the present study, we generated an ideal decellularized rat pancreatic scaffold. Mouse $\mathrm{GFP}^{+}$-iPSCs derived pancreatic $\beta$-like cells were obtained using appropriate growth factors via three steps. Following the cultivation of $\beta$-like cells in the decellularized scaffolds for five days, we evaluated the results via immunofluorescence and qRT-PCR. Our results indicated that mouse $\mathrm{GFP}^{+}$-iPSCs derived pancreatic $\beta$ like cells were well grown and functional. Moreover, the expression of insulin in this three-dimensional culture was higher than those results obtained using a two-dimensional culture. Taken together, our results suggest that pancreatic scaffolds can be used to optimize the generation of $\beta$-like cells derived from iPSCs and as such may represent a therapeutic means of curing diabetes mellitus.

\section{Materials and Methods}

2.1. Pancreas Harvest and Decellularization. All animal work was performed in accordance with the institutional guidelines and was approved by the Animal Ethics Committee of Nantong University. Sprague-Dawley (SD) rats weighing 250-300 g were used for the production of decellularized pancreatic scaffolds. All animals were kept on a $12 \mathrm{~h}$ light/dark cycle with free access to food and water. SD rats were anaesthetized by intraperitoneal injection of sodium pentobarbital intraperitoneally $(1 \%, 1.2 \mathrm{~mL} / 100 \mathrm{~g})$ and anticoagulated by heparin $1000 \mathrm{U}$ i.p. Following anesthetization, an abdominal incision was made. The celiac trunk and the communication branches between the spleen and intestine (stomach) were ligated and divided, and the splenic artery was inserted by an intravenous catheter $(22 \mathrm{G})$ and fixed with 3-0 silk sutures. The cannula in the artery was connected to a peristaltic pump (Masterflex, Thermo Fisher, USA) to permit the flow of the perfusate. A total of $100 \mathrm{~mL}$ phosphate-buffered saline (PBS) was perfused at a speed of $2 \mathrm{~mL} \mathrm{~min}^{-1}$ to clear blood from the pancreas. Subsequently, the pancreas was perfused with $1 \%$ (w/v) Triton X-100 (Amresco)/0.1\% ammonium hydroxide (Xilong Chemical Reagent Co., Ltd.) for $4 \mathrm{~h}$ at a speed of $2 \mathrm{~mL} \mathrm{~min}^{-1}$. Finally, the pancreas was perfused with PBS for $24 \mathrm{~h}$ to rinse cellular debris and maintain isotonicity. The decellularized pancreas scaffold was preserved in PBS containing $100 \mathrm{UmL}^{-1}$ penicillin and $100 \mathrm{UmL}^{-1}$ streptomycin at $4^{\circ} \mathrm{C}$.

2.2. Decellularization Assessment. To examine the morphologic and histological features of the pancreatic scaffolds, tissues were randomly dissected from fresh pancreas and decellularized pancreatic scaffolds $(n=3)$ and fixed with $4 \%$ formaldehyde, dehydrated, and embedded in paraffin. For morphologic studies, tissue sections were deparaffinized and stained with hematoxylin and eosin (H\&E) and Masson' trichrome. For immunohistochemistry, sample sections were blocked with 5\% BSA for half an hour and $0.3 \% \mathrm{H}_{2} \mathrm{O}_{2}$ to inhibit the endogenous peroxidase for $20 \mathrm{~min}$. Subsequently, the sections were incubated with primary antibodies consisting of rabbit anti-collagen I 1:100 (Abcam), rabbit anti-collagen IV 1:100 (Abcam), rabbit anti-laminin 1:100 (Abcam), and rabbit anti-fibronectin 1:100 (Abcam) at $4^{\circ} \mathrm{C}$ overnight. The next day, the slides were incubated with secondary biotinylated goat anti-rabbit antibodies (Zsbio) and visualized using an Olympus microscope.

2.3. DNA and GAG Content Assay. For DNA quantification, the decellularized tissues and the fresh tissues $(n=5)$ were lyophilized and dissected into small pieces of approximately $20 \mathrm{mg}$. DNA was isolated according to the Dneasy Tissue kit protocol (Tiangen, China). The total amount of DNA was measured by ultraviolet spectrophotometer and the DNA content was calculated in the tissue. Quantification of GAG (glycosaminoglycan) was measured using the GAG assay kit (Hermes Criterion Biotechnology). Decellularized tissues and fresh tissues $(n=3)$ were dissected into small pieces weighing $10 \mathrm{mg}$ and analyzed according to the manufacturer's instructions. Following ultraviolet spectrophotometer measurements, the GAG content was calculated in the tissues.

2.4. Scanning Electron Microscopy (SEM). Decellularized and fresh pancreas were fixed in $2.5 \%$ glutaraldehyde in PBS overnight and subsequently washed three times, for $10 \mathrm{~min}$ utes each. The samples were fixed in the dark using $1 \%$ osmic acid for $2 \mathrm{~h}$, followed by another three PBS washes for $10 \mathrm{~min}$ each. Subsequently, the samples were dehydrated in gradient series of alcohol for $15 \mathrm{~min}$ each. Subsequently, the samples were treated with isoamyl acetate and then sputter-coated with gold after critical point dried. Images were observed using scanning electron microscopy (HITACHI).

2.5. In Vivo Implantation of Decellularized Pancreas. Male C57BL/6 mice $(n=3)$, age 7-8 weeks, were anesthetized as mentioned above and the sterile scaffolds were sectioned into $5 \times 5 \times 2 \mathrm{~mm}^{3}$ sections to be implanted. The dorsal side was sterilized by iodophor and the surgical operation 
was performed under sterile conditions. A $1 \mathrm{~cm}$ incision was made in dorsal and a pocket similar to the implanted scaffolds was created to cover it. The incision was closed with 5-0 sutures and sterilized using iodophor for three days following the operation. At selected time points $(3,7,14,21$, and 28 days), the sections were harvested and fixed in $4 \%$ paraformaldehyde for $\mathrm{H} \& \mathrm{E}$ staining.

2.6. Characterization of iPSCs. The mouse $\mathrm{GFP}^{+}$-iPSCs were kindly provided by Stem Cell Bank, Chinese Academy of Sciences [20]. Alkaline phosphatase staining and teratoma formation are usually implemented to identify the iPSCs. Teratoma formation is considered as the gold standard for confirming pluripotency of iPSCs [21]. For in vivo experiments, we injected $5 \times 10^{6}$ mouse $\mathrm{GFP}^{+}$-iPSCs into the dorsal flanks of 5 -week-old NOD/SCID mice $(n=6)$. Tumor formation was observed after three weeks and the tumors were resected on the fifth week. The samples were fixed with $4 \%$ formaldehyde, dehydrated, embedded in paraffin, and cut into $5 \mathrm{um}$ thick sections. After being deparaffinized and stained with haematoxylin and eosin (H\&E), alkaline phosphatase staining was implemented according to the instructions provided by the alkaline phosphatase detection kit (Millipore). Slides were visualized using an Olympus microscope.

2.7. In Vitro Differentiation of Mouse $\mathrm{GFP}^{+}$-iPSCs into Pancreatic $\beta$-Like Cells. Mouse $\mathrm{GFP}^{+}$-iPSCs were induced to differentiate into pancreatic $\beta$-like cells using a three-stages protocol described by Alipio et al. [9] and Schroeder et al. [22]. Stage one is as follows: $\mathrm{GFP}^{+}$-iPSCs were induced to embryoid bodies (EBs). $\mathrm{GFP}^{+}$-iPSCs were detached into single cell using $0.25 \%$ trypsin (sigma) and plated onto a $10 \mathrm{~cm}$ culture dish for $1 \mathrm{~h}$ to remove the feeder cells. The feeder-depleted cells were collected, centrifuged at $400 \mathrm{~g}$ for $5 \mathrm{~min}$, and resuspended into EBs medium containing knockout DMEM (Gibco), 15\% FBS (sigma), 2 mM Lglutamine (Gibco), $1 \times 10^{-4} \mathrm{M}$ nonessential amino acids (Gibco), $1 \times 10^{-4} \mathrm{M}$ 2-mercaptoethanol (Sigma), and $1 \mathrm{x}$ penicillin-streptomycin (Gibco). The cells were suspended in EBs medium, 5000 cells per milliliter, transferred to ultralow attachment plates (corning), and incubated for 3 days. Stage two is as follows: EBs were induced to multilineage progenitors. The EBs whose average size was 500 um were collected and transferred to $10 \mathrm{~cm}$ plates coated by $0.1 \%$ gelatin (sigma). Each plate contained 8-12 EBs and was incubated for another 9 days with EBs medium, which was replaced every 3 days. Stage three is as follows: EBs were induced to $\beta$-like cells. EBs medium was replaced by selective differentiation medium containing DMEM/F12 (corning), 15\% FBS (sigma), $20 \mathrm{nM}$ progesterone (Sigma), $100 \mu \mathrm{M}$ putrescine (Sigma), $1 \mu \mathrm{g} / \mathrm{mL}$ laminin (Sigma), $10 \mathrm{mM}$ nicotinamide (Sigma), 1x ITS (Gibco), B27 media supplement (Gibco), and 1x penicillin-streptomycin (Gibco). On the sixth day, the cells were trypsinized and transferred into T25 tissue culture flask for 14 days with medium changed every 3 days.

2.8. Characterization of Pancreatic $\beta$-Like Cells. The mouse $\mathrm{GFP}^{+}$-iPSCs derived $\beta$-like cells were characterized by immunofluorescence (IF) and qRT-PCR. For IF, cells were fixed by $4 \%$ paraformaldehyde for $20 \mathrm{~min}$, permeabilized by $0.1 \%$ Triton X-100 for $10 \mathrm{~min}$, and blocked with 5\% BSA for $30 \mathrm{~min}$. After that, the cells were incubated with primary antibodies overnight at $4^{\circ} \mathrm{C}$ including rabbit anti-insulin 1:100 (Abcam), rabbit anti-C-peptide 1:100 (Abcam), and rabbit anti-Glucagon 1:100 (Abcam). The next day, the cells were washed three times in PBS and incubated with secondary antibodies including Alexa Flour 594-conjugated goat antirabbit 1:500 for insulin, c-peptide, and glucagon at room temperature for 1 hour. Subsequently, the cells were stained with Hoechst (sigma) for 15 min followed by 3 changes of PBS changes. The cells were visualized using an Olympus fluorescence microscope. For qRT-PCR, TRIzol reagent (Life Technologies) was used to extract total RNA from $\beta$-like cells, according to the manufacturer's instruction. RNA was reverse-transcribed into cDNA using RevertAid ${ }^{\mathrm{TM}}$ First Strand cDNA Synthesis Kit (Fermentas). Gene expression levels of insulin, glucagon, PDX-1, islet-1, Nkx6.1, and HNF6 were analyzed by qRT-PCR. The reaction mixtures included $10 \mu \mathrm{L}$ SYBR Green Master (Roche), $4 \mu \mathrm{L}$ Template DNA, $1 \mu \mathrm{L}$ forward primer, $1 \mu \mathrm{L}$ reverse primer, and $4 \mu \mathrm{L}$ DEPC water. PCR primer sequences for the specific pancreatic markers are shown in Table 1. The 7500 Real-Time PCR System (Applied Biosystems) was used for cDNA amplification. The amplification protocol included $5 \mathrm{~min}$ at $94^{\circ} \mathrm{C}$ for initial denaturation, followed by 40 cycles of $30 \mathrm{~s}$ at $94^{\circ} \mathrm{C}$ for denaturation, $30 \mathrm{~s}$ at $60^{\circ} \mathrm{C}$ for annealing, and final extension at $72^{\circ} \mathrm{C}$ for $30 \mathrm{~s}$. To prove whether the differentiated pancreatic beta-like cells were teratogenic after differentiation, teratoma formation was taken as mentioned above.

2.9. Insulin Release Assays. Stage-three cells were trypsinized and transferred into new Petri dishes for $12 \mathrm{~h}$. After being preincubated in glucose-free Krebs-Ringer bicarbonate buffer (KRB) for $90 \mathrm{~min}$, the cells were incubated with KRB containing $0,5,15,30$, and $45 \mathrm{mM}$ glucose for $90 \mathrm{~min}$. The supernatant was collected and frozen at $-80^{\circ} \mathrm{C}$ to be detected. Insulin assay was performed by ultrasensitive mouse insulin assay kit (Mercodia) according to the manufacturer's instruction.

2.10. Mouse GFP ${ }^{+}$-iPSCs Derived $\beta$-Like Cells Seeding and Dynamic Culturing. Before seeding $\beta$-like cells, the sterile scaffold was perfused with a medium consisting of DMEM/F12 with 15\% FBS through the circulation perfusion device for 1 hour. $\beta$-like cells were plated into scaffolds using two methods including vascular perfusion and multipositional parenchymal injection as previously described. $\beta$-like cells $\left(3 \times 10^{7}\right)$ were trypsinized and suspended in $1 \mathrm{~mL}$ of medium. Approximately $0.4 \mathrm{~mL}$ of medium was injected into the decellularized pancreatic scaffold through the splenic artery and $0.6 \mathrm{~mL}$ medium through the multipositional parenchymal injection. The scaffold was allowed to incubate for $30 \mathrm{~min}$ to facilitate cell adherence. The medium was subsequently seeped out from the scaffold and the remaining cells were resuspended in $1 \mathrm{~mL}$ of medium to reperfuse the scaffold. The scaffold was allowed to incubate for $2 \mathrm{~h}$ prior to being linked to the circulation perfusion device. Finally, 
TABLE 1: PCR primer sequences for specific pancreatic markers.

\begin{tabular}{|c|c|c|}
\hline Gene & GenBank accession number & Primer \\
\hline GAPDH & NM_000072.6 & \\
\hline Forward primer & & AAGAAGGTGGTGAAGCAGG \\
\hline Reverse primer & & GAAGGTGGAAGAGTGGGAGT \\
\hline Insulin & NM_000085.6 & \\
\hline Forward primer & & AGTTGAGTTGGGCAGAATAGG \\
\hline Reverse primer & & TCCAAAGGGCACCGTAT \\
\hline Glucagon & NM_000068.7 & \\
\hline Forward primer & & CCAGCGACTACAGCAAATACC \\
\hline Reverse primer & & GAGAAGGAGCCATCAGCGT \\
\hline HNF6 & NM_000075.6 & \\
\hline Forward primer & & CGTTACAGCATCCCACAG \\
\hline Reverse primer & & AGCCACTTCCACATCСТC \\
\hline Nkx6.1 & NM_144955.2 & \\
\hline Forward primer & & GAAAACACACCAGACCCA \\
\hline Reverse primer & & GGAACCAGACCTTGACCT \\
\hline Islet-1 & NM_021459.4 & \\
\hline Forward primer & & CACCTTGCGGACCTGCTAT \\
\hline Reverse primer & & AGGGCGGCTGGTAACTTTG \\
\hline Pdx-1 & NM_008814.3 & \\
\hline Forward primer & & CGGAACCCGAGGAAAACA \\
\hline Reverse primer & & CGAGGTCACCGCACAATCT \\
\hline
\end{tabular}

the scaffold was linked to the device through splenic artery to allow perfusion feeding of media at the speed of $1.2 \mathrm{~mL} / \mathrm{min}$. After five days of culture at $37^{\circ} \mathrm{C}$, the seeded scaffolds were analyzed using HE staining, immunofluorescence, and qRTPCR as previously described.

2.11. Statistical Analysis. Statistical analysis was performed using SPSS 19 software. Statistical differences were identified using a Kruskal-Wallis test when $p$ value of less than 0.05 was obtained.

\section{Results}

3.1. Perfusion Decellularization of Rat Pancreas. SD rat pancreases were decellularized using $10 \%$ Triton X-100/0.1\% ammonium hydroxide solution. A gradual change of color was observed during the decellularization process. The blood was first washed out and the pancreas turned semitransparent after 15 minutes of perfusion with PBS (Figure 1(b)). Following perfusion with $1 \%$ Triton X-100/0.1\% ammonium hydroxide (about $3 \mathrm{~h}$ ), the pancreas quickly became transparent (Figure 1(c)) and the anatomical structure of decellularized pancreas was well retained and visualized according to the vasography and anatomic microscope (Figure $1(\mathrm{~d}))$. H\&E staining showed no residual cells following decellularization, as compared to the native pancreas (Figures 2(a) and 2(b)). The result of Masson's trichrome staining also confirmed that most of the collagen fiber components and vascular structure were well retained (Figures 2(c) and 2(d)). Immunohistochemical analysis of ECM in the native pancreas and scaffold demonstrated that collagen I (Figures 2(e) and 2(i)), collagen IV (Figures $2(\mathrm{f})$ and $2(\mathrm{j})$ ), fibronectin (Figures 2(g) and 2(k)), and laminin (Figures 2(h) and 2(l)) were preserved following complete decellularization. Quantitative DNA analysis demonstrated that the DNA content of decellularized pancreas scaffolds was $43.96 \pm 4.07 \mathrm{ng} / \mathrm{mg}$ dry weight in contrast to $5666 \pm 360.9 \mathrm{ng} / \mathrm{mg}$ for the native pancreas (Figure 3(a)) $\left({ }^{*} p<0.05\right)$. The GAG content in the decellularized pancreatic scaffolds was $30.9 \pm 2.93 \mathrm{ng} / \mathrm{mg}$ wet weight compared to $41.9 \pm 2.74 \mathrm{ng} / \mathrm{mg}$ wet weight in normal pancreas. These results confirmed that about $70 \%$ of GAG was preserved in the decellularized pancreatic scaffold after the decellularization (Figure 3(b)) $\left({ }^{*} p<0.05\right)$.

3.2. SEM Examination. The microstructure of the native and decellularized scaffolds was evaluated by SEM. No residual cells were retained and the integrity of three-dimensional ECM microstructure of the decellularized pancreatic scaffolds was largely preserved (Figures 4(a) and 4(b)). In general, the decellularized rat pancreas scaffolds possessed a microstructure similar to the native pancreas.

3.3. Biocompatibility Assay. To evaluate the in vivo biocompatibility of the decellularized rat pancreatic scaffolds, the implanted scaffolds were removed on the following schedule after surgery (days 3, 7, 14, and 21). The scaffolds retained their appearance and texture. $\mathrm{H} \& \mathrm{E}$ staining revealed mononuclear cells that began to permeate through the scaffold by day 3 and reached the peak on day 7 . The number of inflammatory cells diminished until there were a few remaining by day 21 (Figure 5). Throughout the entire observation period, few 


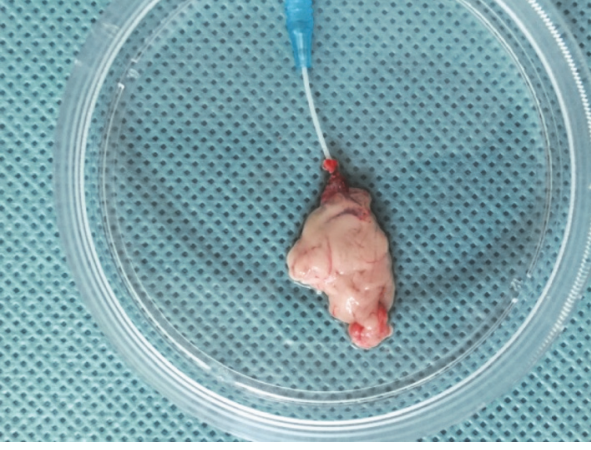

(a)

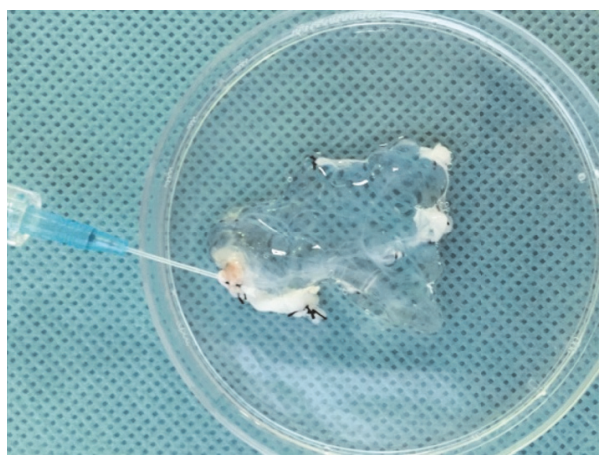

(c)

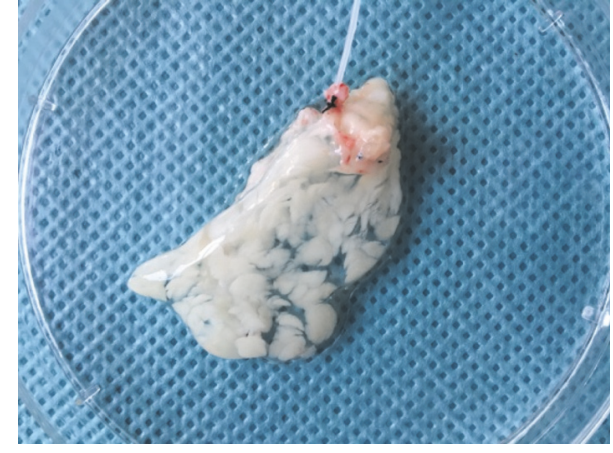

(b)

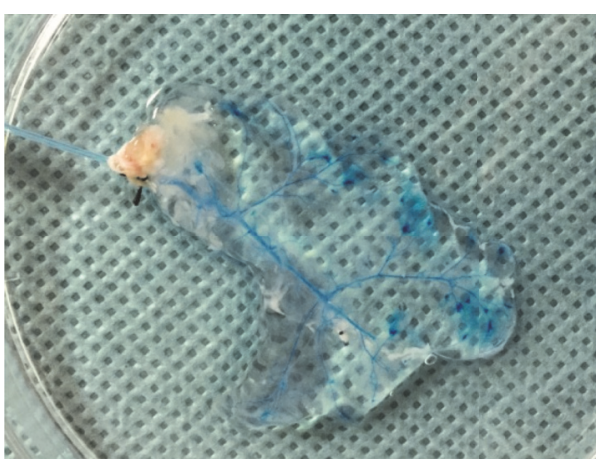

(d)

FIgURE 1: Pancreas harvest and decellularization. (a) The pancreas was separated from adjacent tissue. (b) Following perfusion with PBS, the pancreas became semitransparent. (c) Following perfusion with $1 \%$ Triton X-100/0.1\% ammonium hydroxide, the pancreas quickly became transparent and maintained the original shape. (d) Vasography clearly showed the vascular system.

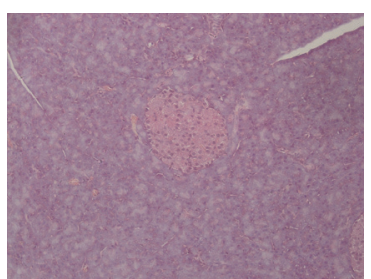

(a)

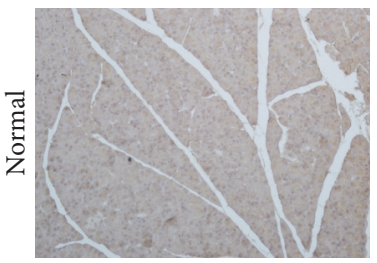

(e)

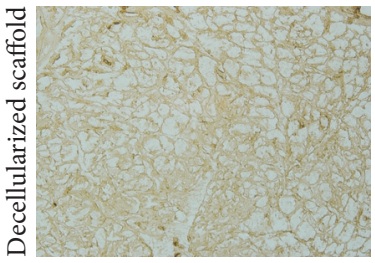

(i)

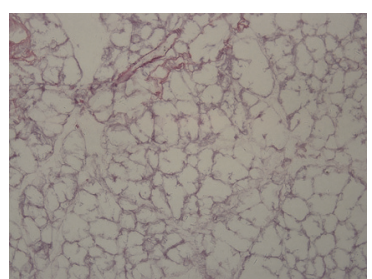

(b)

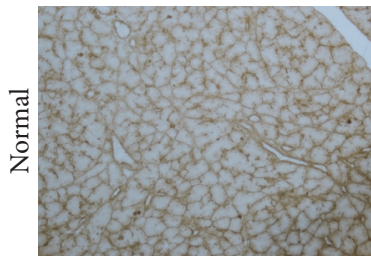

(f)

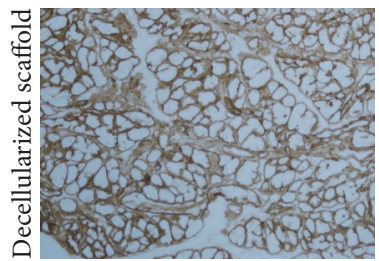

(j)

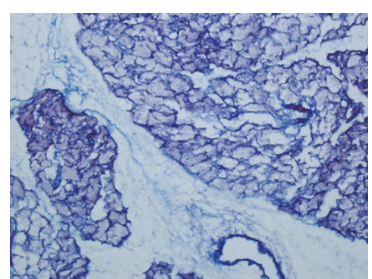

(c)

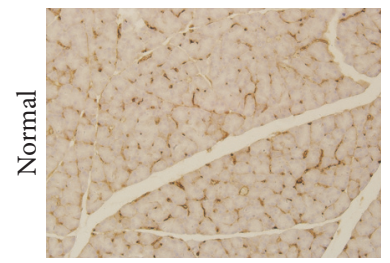

(g)

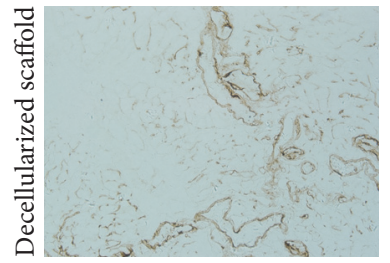

(k)

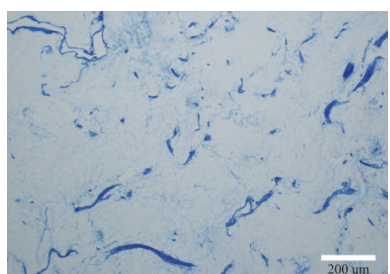

(d)

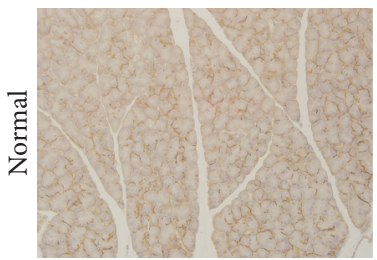

(h)

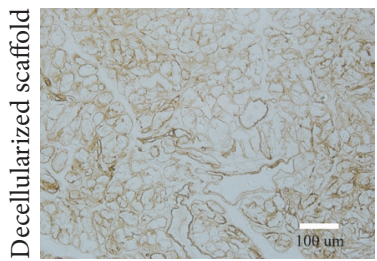

(1)

Figure 2: Analyzation of ECM components. ( $a, b)$ H\&E staining of the normal pancreas and decellularized pancreatic scaffold. (c, d) Masson's trichrome of the normal pancreas and decellularized pancreatic scaffold. Immunohistochemical analysis of the normal pancreas and decellularized pancreatic scaffold: (e, i) collagen I, (f, j) collagen IV, (g, k) fibronectin, and (h, l) laminin. 


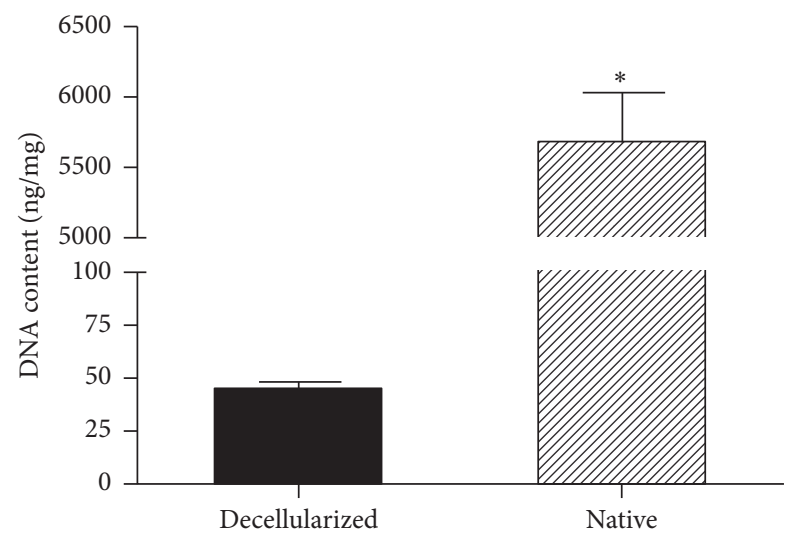

(a)

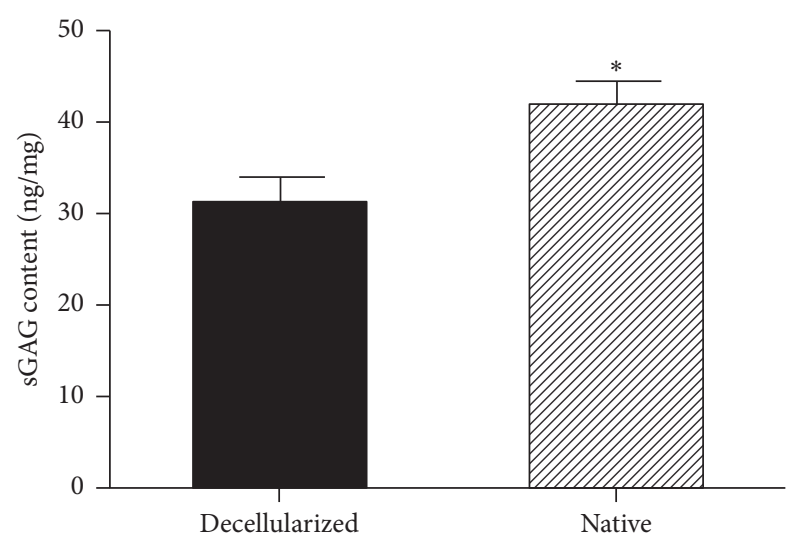

(b)

FIGURE 3: DNA and GAG content assay. (a) Quantitative DNA analysis demonstrated that the DNA content of the decellularized pancreas scaffolds was $43.96 \pm 4.07 \mathrm{ng} / \mathrm{mg}$ dry weight in contrast to $5666 \pm 360.9 \mathrm{ng} / \mathrm{mg}$ for the native pancreas $\left({ }^{*} p<0.05\right)$. (b) The GAG content in the decellularized pancreatic scaffolds was $30.9 \pm 2.93 \mathrm{ng} / \mathrm{mg}$ wet weight compared to $41.9 \pm 2.74 \mathrm{ng} / \mathrm{mg}$ in the normal pancreas $\left({ }^{*} p<0.05\right)$.

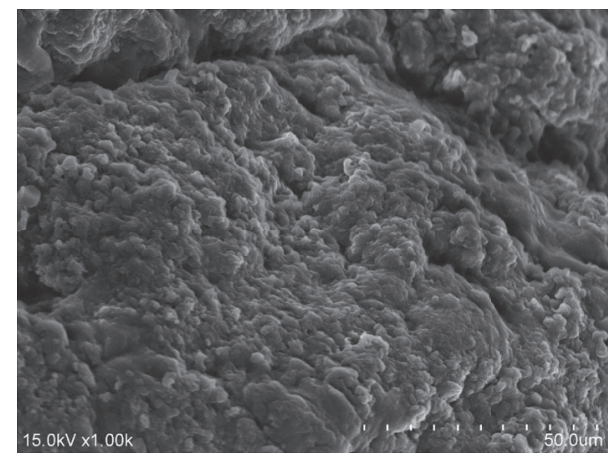

(a)

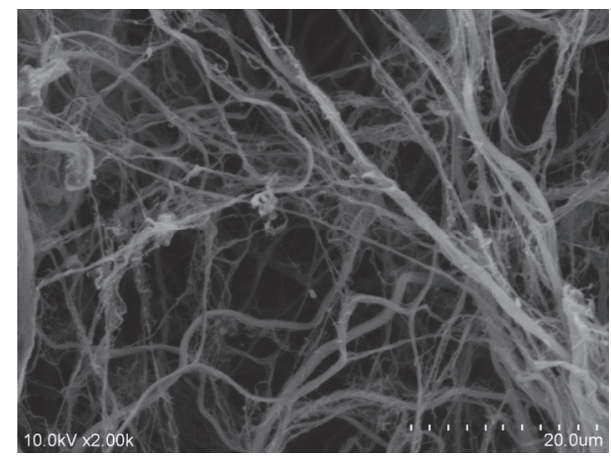

(b)

FIgURE 4: Scanning electron microscopy. (a, b) SEM showed the microstructure of the native and decellularized pancreatic scaffolds. No residual cells were retained and the integrity of microstructure were largely preserved.

macrophagocytes or other pathological signs were observed, suggesting that the decellularized pancreas scaffolds were biocompatible.

3.4. Identification of iPSCs and Pancreatic $\beta$-Like Cells. For alkaline phosphatase staining, the $\mathrm{GFP}^{+}$-iPSCs were purple which showed positive alkaline phosphatase staining (Figure 6(a)). For teratoma formation, $5 \times 10^{6}$ mouse $\mathrm{GFP}^{+}$iPSCs were injected into the dorsal flanks of 5-week-old NOD/SCID mice. Five weeks following injection, a tumor of $2.5 \times 1.5 \times 1.5 \mathrm{~cm}^{3}$ in size was formed and resected (Figures 6(b) and 6(c)). Using hematoxylin and eosin staining, we determined that tumor tissue was derived from all three germinal layers, including glandular epithelium (endoderm), cartilage epithelium (mesoderm), and cornified epithelium (ectoderm). When it came to the pancreatic $\beta$-like cells, there was no teratoma formation in all NOD/SCID mice.

3.5. Selective Differentiation of Mouse GFP ${ }^{+}-i P S C s$ into Pancreatic $\beta$-Like Cells. Mouse $\mathrm{GFP}^{+}$-iPSCs were differentiated into $\beta$-like cells in three stages. At stage $1, \mathrm{GFP}^{+}$-iPSCs were detached into single cells and resuspended in EBs medium in ultra-low attachment plates for three days, where they formed EBs (Figure 7(b)). At stage 2, the EBs were transferred to an adherent culture and differentiated into multilineage progenitors for 9 days. During this time, cells migrated from EBs and grew by adherence. At stage 3, which lasted 21 days, the cells were trypsinized and resuspended in fresh selective medium. Numerous clusters began to form on day 14 (Figure 7(c)), and on day 21, large clusters were evident (Figure 7(d)). To evaluate the efficiency of differentiation, immunofluorescent staining and qRT-PCR were performed. The cells were positive for insulin, C-peptide, and glucagon by immunofluorescence (Figure 8). qRT-PCR confirmed the immunofluorescence findings, indicating higher expression of the previously mentioned markers on day 21 as compared to day 14 controls and $\mathrm{GFP}^{+}$-iPSCs (Figures 9(a) and 9(b)). Hormones expressed by pancreatic endocrine cell included $\alpha$ and $\beta$, suggesting that the differentiated cells had progressed into mature $\beta$-like cells. Also, some reliable markers in the development of the pancreatic $\beta$ cells including PDX-1, islet-1, Nkx6.1, and HNF6 were expressed higher on day 21 compared to day 14 and the undifferentiated iPSCs (Figures 9(c)-9(f)). 

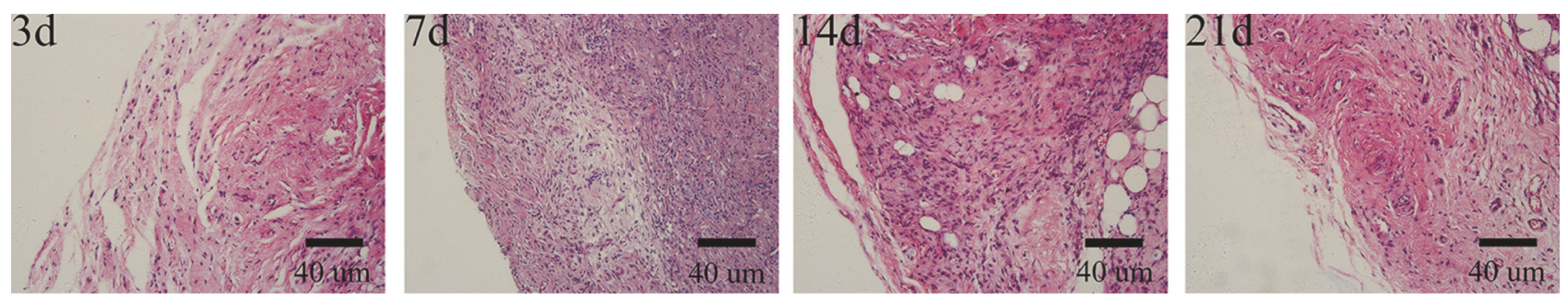

FIGURE 5: Biocompatibility assay. Inflammatory cells began to infiltrate into the scaffold on day 3, reaching a peak on day 7. The inflammatory response subsequently began to reduce and there were few inflammatory cells on day 21 . The scaffolds retained their appearance and texture.
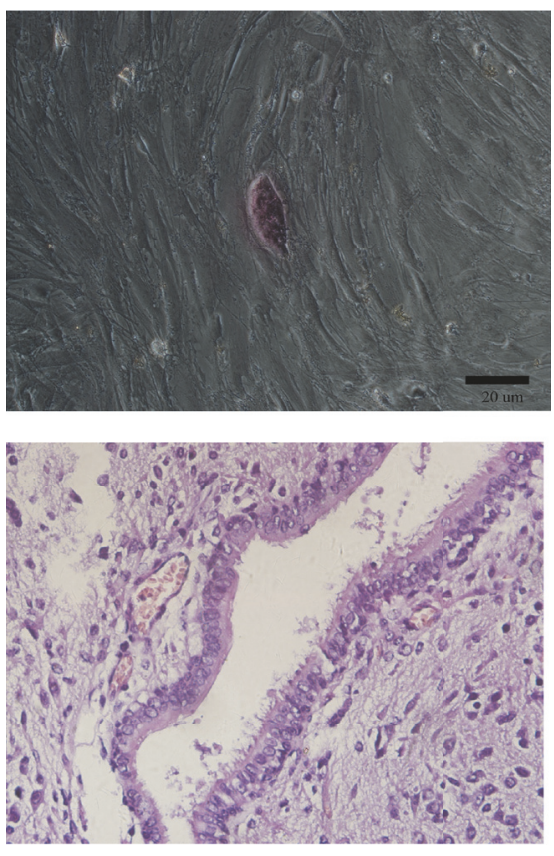

Endoderm

(a)
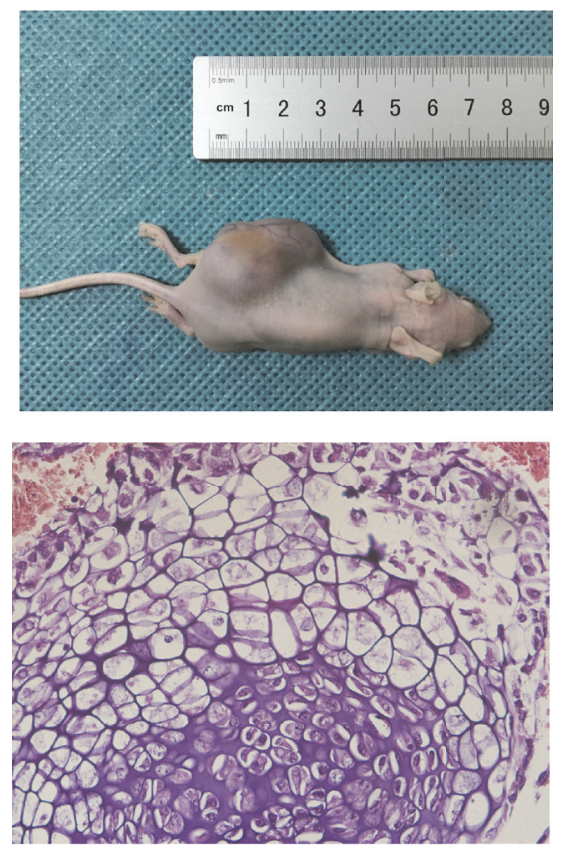

Mesoderm

(b)
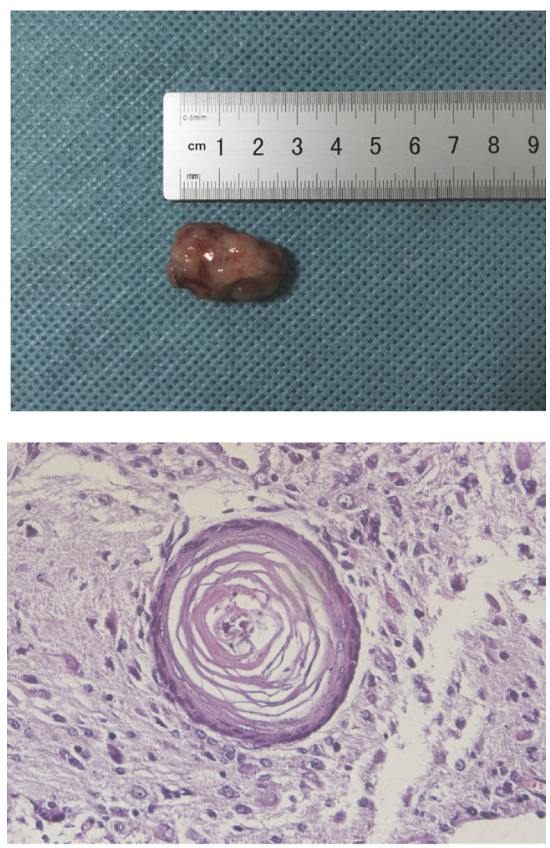

Ectoderm

(c)

FIgURE 6: Identification of iPSCs. (a) The GFP ${ }^{+}$-iPSCs were purple which showed positive alkaline phosphatase staining. (b, c) Five weeks following injection, a $2.5 \times 1.5 \times 1.5 \mathrm{~cm}^{3}$ size tumor formed. Using hematoxylin and eosin staining, tumor tissue was noted to be derived from all three embryonic layers, including glandular epithelium (endoderm), cartilage (mesoderm), and cornified epithelium (ectoderm).

To decide whether the differentiated cells were glucose responsive, the $\beta$ cells were exposed to a glucose gradient $(0 \mathrm{mM}, 5 \mathrm{mM}, 15 \mathrm{mM}, 30 \mathrm{mM}$, and $45 \mathrm{mM})$ and insulin release was measured by ELISA assay. At a glucose concentration of $0 \mathrm{mM}$, insulin secretion was hardly detected. However, at the $5 \mathrm{mM}, 15 \mathrm{mM}, 30 \mathrm{mM}$, and $45 \mathrm{mM}$ glucose concentration, insulin was detected at $0.724 \pm 0.098 \mathrm{ng} / 10^{5}$, $0.902 \pm 0.078 \mathrm{ng} / 10^{5}, 1.844 \pm 0.102 \mathrm{ng} / 10^{5}$, and $0.558 \pm$ $0.150 \mathrm{ng} / 10^{5}$ cells, respectively (Figure 10 ).

3.6. $\mathrm{GFP}^{+}$-iPSCs Derived $\beta$-Like Cells in Decellularized Pancreatic Scaffolds. To evaluate $\mathrm{GFP}^{+}$-iPSCs derived $\beta$-like cells in decellularized rat pancreatic scaffolds, $\beta$-like cells were plated into scaffolds using two methods: vascular perfusion and multipositional parenchymal injection. Approximately $3 \times 10^{7}$ cells were plated into the scaffolds with a total engraftment rate of $83.6 \pm 4.8 \%$. Following stewing for $2 \mathrm{~h}$, the scaffold was linked to the dynamic perfusion device through splenic artery with culture media which was changed daily (Figure 11). After five days of perfusion culture, the scaffold was harvested and analyzed by H\&E staining, IHC, and qRT-PCR. H\&E staining revealed that $\beta$-like cells engrafted the parenchymal region (Figure 12(a)) and IHC demonstrated that engrafted cells maintained insulin, C-peptide, and glucagon expression (Figures 12(b), 12(c), and 12(d)). Moreover, insulin expression in the perfusion culture was nearly 2-fold higher than those levels obtained by traditional culturing $\left({ }^{*} p<0.05\right)$ (Figure 13). Taken together, these results demonstrate that the decellularized pancreas is cytocompatible and maintainable of function.

\section{Discussion}

Our research focused on combining iPSCs derived pancreatic $\beta$-like cells with whole organ acellular pancreatic scaffold methods. By simulating the in vivo microenvironment, we 

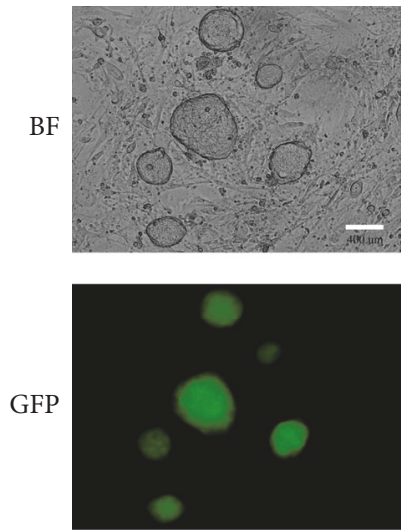

iPSCs

(a)
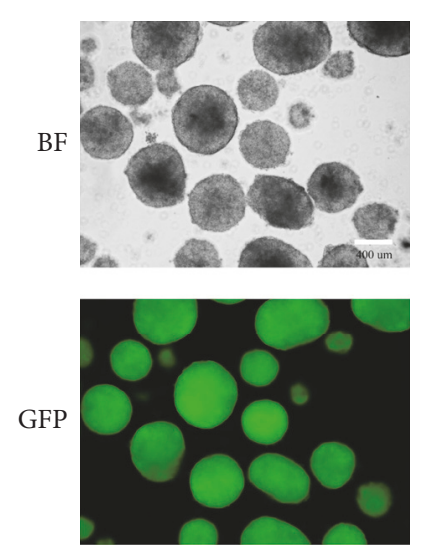

EBs

(b)
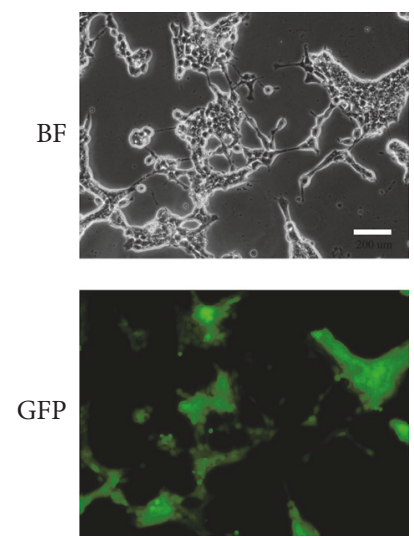

Stage 3: day 14

(c)
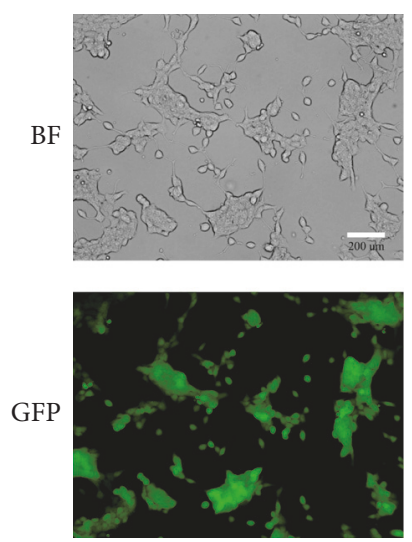

Stage 3: day 21

(d)

FIGURE 7: Selective differentiation of iPS cells into insulin-producing pancreatic $\beta$-like cells. Morphologies of mouse GFP ${ }^{+}$-iPSCs differentiated into $\beta$-like cells: (a) undifferentiated GFP ${ }^{+}$-iPSCs. (b) In the first stage, $\mathrm{GFP}^{+}$-iPSCs resuspended on ultra-low attachment plates for three days forming EBs. (c) The third stage on day 14: differentiated cells grew together closely. (d) The third stage on day 21: cells grew well and gathered liked islets.

confirmed the differentiation and functionality of iPSCs into $\beta$-like cells. These results provide a novel means of exploring the function and efficacy of generating iPSCs derived pancreatic $\beta$-like cells in vitro as in vivo and, importantly, may provide a means of curing diabetes mellitus via recellularized pancreatic scaffolds.

Currently, stem cells including pancreatic islet stem cells, embryonic stem cells, mesenchymal stem cells, and induced pluripotent stem cells [23] have been suggested as a means to regenerate the pancreas. This approach has been deemed the most promising way of solving overcoming limitations associated with diabetes-related transplantation. iPSCs, differentiated with multidirectional potential, can resemble ES cells, via reprogramming of somatic cells [24]. This revolutionary discovery has had a broad impact on pathology research [25], drug screening, cell transplantation therapy [26], tissue engineering, and regenerative medicine [27]. iPSCs can be derived from host somatic cells, are easy to obtain, can expand rapidly, and, most importantly, have lower immunogenicity as compared to transplants using donor-derived cells or tissues. In addition, iPSCs avoid ethical implications which have clouded the use of embryonic stem cells [28]. iPSCs are usually identified utilizing alkaline phosphatase staining, immunostaining of makers of stem cells, EB formation, teratoma formation, Karyotype analysis, and so on. Teratoma formation is considered as the gold standard for confirming pluripotency of iPSCs. Nude mouse tumorigenicity assay proved the multipotent capacity of the iPSCs $[29,30]$. For the past few years, iPSCs have been successfully differentiated into neurons [31], cardiac muscle cells [32], and hematopoietic cells [33] among other cell types. While the current most effective strategy to cure diabetes is islet or $\beta$ cell transplantation, the shortage of donor, low survival rate of the grafted cells, and immune rejection following transplantation limit the success of this approach. As such, the use of reprogrammed $\beta$ cells derived from autologous stem cells has tremendous potential [34] to solve the transplant-related shortage of the donor and also bypass the immune rejection associated with transplantation. In the present study, we adopted the three-step procedure described by Alipio et al. [9] to induce $\mathrm{GFP}^{+}$-iPSCs into pancreatic $\beta$-like cells. $\mathrm{GFP}^{+}$iPSCs were resuspended on ultra-low attachment plates for three days to form EBs. Compared to other methodologies, this approach was easy to operate and generated more EBs. EBs were subsequently transferred onto an adherent culture for nine days where EBs differentiated into multilineage progenitors. Through the use of selective medium over the course of a 21-day period, the cells developed into pancreatic $\beta$ cells. Immunofluorescence and qRT-PCR independently confirmed the presence of insulin, C-peptide, and glucagon which reached its peak on day 33. Also, some reliable markers in the development of the pancreatic $\beta$ cells were expressed higher on day 21 compared to day 14 and the undifferentiated iPSCs. PDX-1 plays a crucial role in beta-cell differentiation and transactivates the insulin gene [35]. During the pancreas development, PDX-1 is expressed in precursor cells but becomes restricted to $\beta$-cells in mature pancreas. Islet-1 is an important transcription factor expressed in pancreatic islet cells [36]. It is important for the survival and differentiation of pancreatic endocrine progenitors. Lack of islet-1 will affect insulin secretion and islet transcriptome. Nkx6.1 is essential for maintaining the functional and molecular traits of mature beta cells [37]. HNF6 directly activates the proendocrine transcription factor and is significant for endocrine differentiation [38]. Those improving expressions of crucial gene in the development of pancreas indicated that the differentiated model is mature. Previous groups have used different factors to induce differentiation including fibroblast growth factor, epidermal growth factor, retinoic acid, and activin $\mathrm{A}$, but these may induce neuronal (i.e., nerve cell) differentiation [39]. Our experiment approach conversely does not add these factors and as such avoids these risks. The insulin secretion 

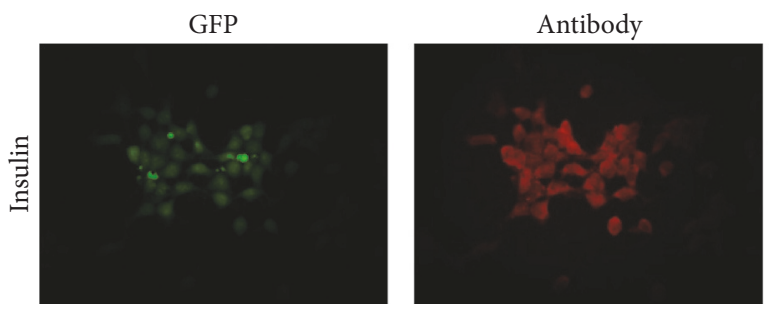

(a)
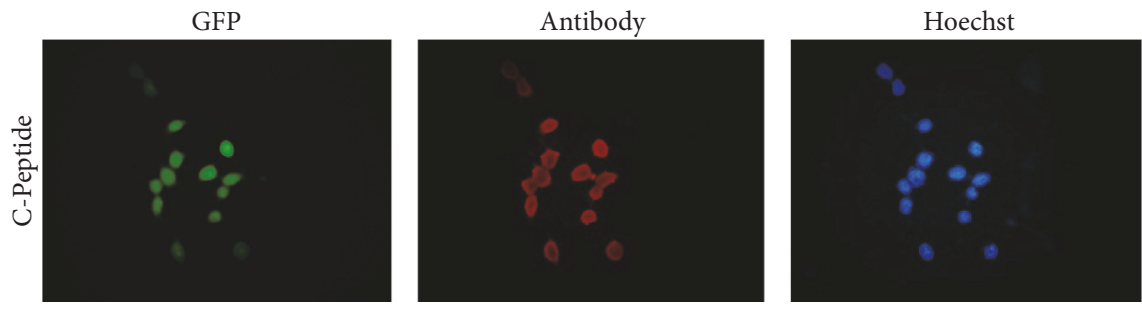

(b)
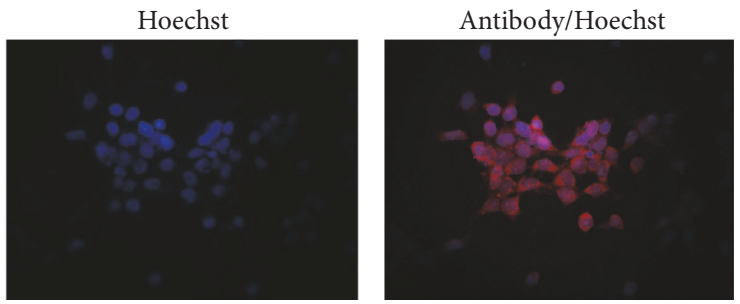

)
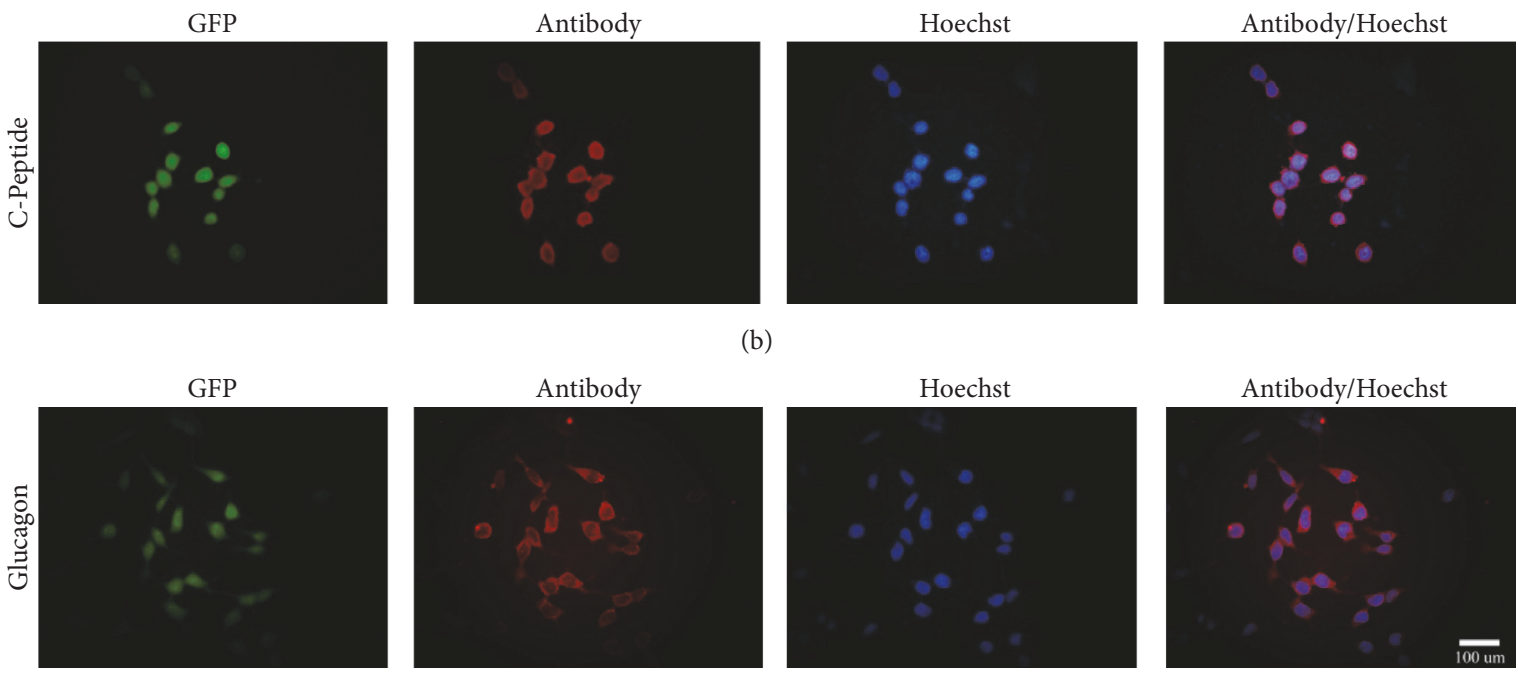

(c)

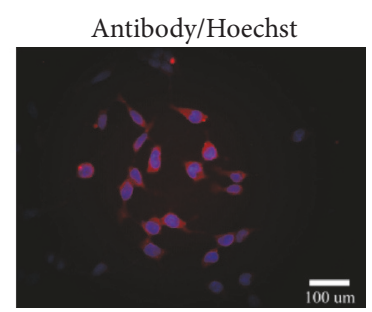

FIGURE 8: Immunofluorescent of $\mathrm{GFP}^{+}$-iPSCs derived $\beta$-like cells. $(\mathrm{a}, \mathrm{b}, \mathrm{c})$ The $\mathrm{GFP}^{+}$-iPSCs derived $\beta$-like cells were positive for insulin, C-peptide, and glucagon.

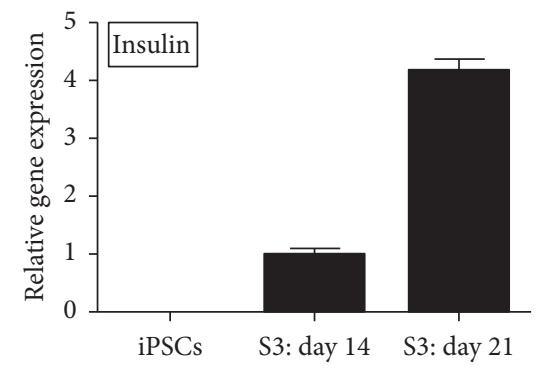

(a)

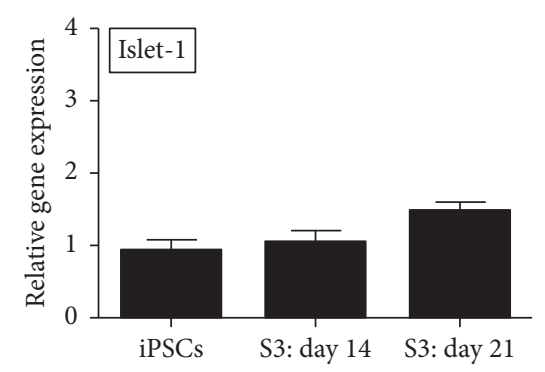

(d)

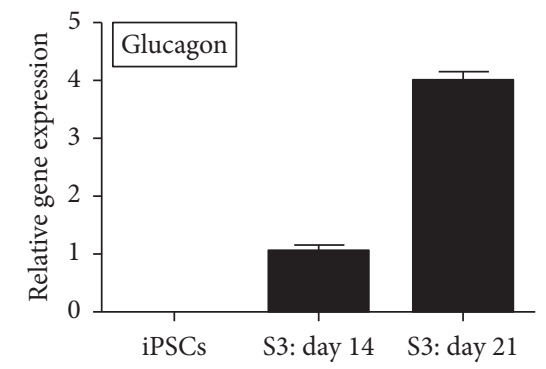

(b)

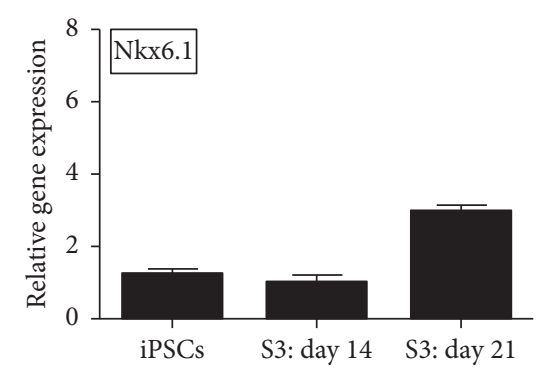

(e)

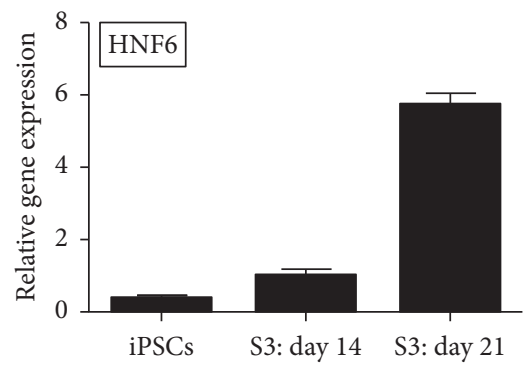

(c)

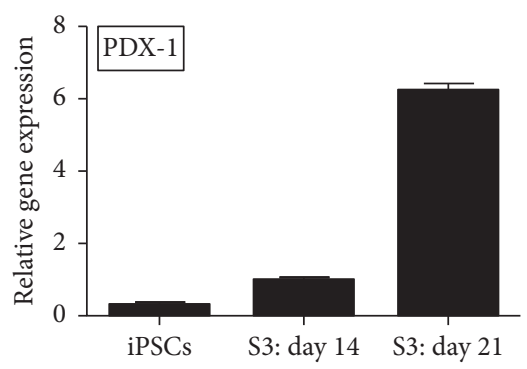

(f)

FIGURE 9: qRT-PCR by the $\beta$-like cells in vitro. (a-f) qRT-PCR demonstrated elevated expression of insulin, glucagon, HNF6, islet-1, Nkx6.1, and PDX-1 on day 21 compared with day 14 and undifferentiated iPSCs. 


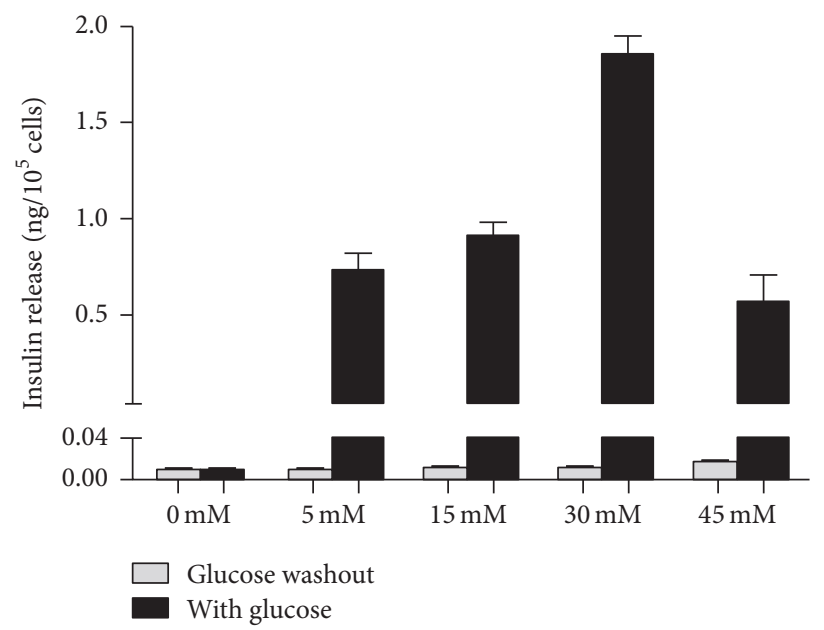

FIGURE 10: Insulin release assays. Insulin secretion was $0.724 \pm 0.098 \mathrm{ng} / 10^{5}$ cells, $0.902 \pm 0.078 \mathrm{ng} / 10^{5}$ cells, $1.844 \pm 0.102 \mathrm{ng} / 10^{5}$ cells, and $0.558 \pm 0.150 \mathrm{ng} / 10^{5}$ cells at a glucose concentration of $5 \mathrm{mM}, 15 \mathrm{mM}, 30 \mathrm{mM}$, and $45 \mathrm{mM}$. By contrast, no insulin was produced when glucose was washed out.
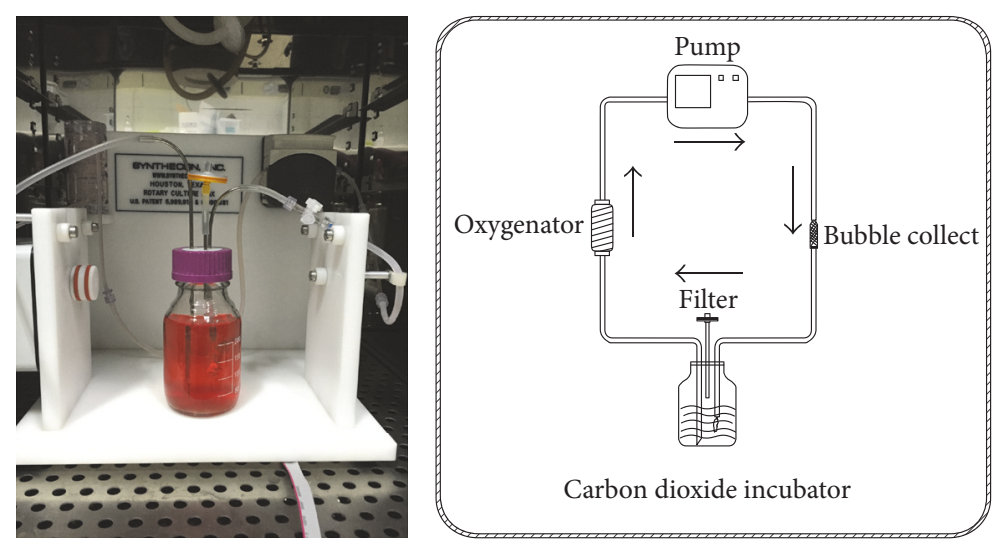

FIGURE 11: $\beta$-like cells were planted into scaffolds. The perfusion device consisted of peristaltic pump, oxygenator, bubble collect, culture bottle, and convey tubes. The GFP ${ }^{+}$-iPSCs derived $\beta$-like cells in the scaffold were cultured for 5 days.

was $1.844 \pm 0.102 \mathrm{ng} / 10^{5}$ cells when exposed to the glucose concentration of $30 \mathrm{mM}$. It needs about 3.1-3.4 $\times 10^{5}$ cells to produce a physiological range of insulin content since the mouse blood volume is about $1.5 \mathrm{~mL}$ and its physiological value of insulin is about $4 \mu \mathrm{g} / \mathrm{L}$. While the approach is promising, more research is needed to further characterize the in vitro differentiation process. As the seeded cells for tissue engineering, optimizing the differentiated cells is of great importance.

Currently, a number of biomaterial scaffolds are being used to evaluate cell function in vitro including hydrogels, chitosan, silk fibroin, collagen type I gel sandwich culture [40], and 3D matrices. In spite of the advantages of these models, these systems cannot evaluate the long-term cell biology, physiology, and chronic effects of toxicity. In recent years, whole organ decellularized scaffolds have been proposed as a novel means of ameliorating scaffold-based analysis. Decellularized scaffolds not only provide space for cell growth but also promote cell migration, differentiation, and metabolism through interactions with the cell matrix. Ion detergent SDS and nonionic detergent Triton-100 are frequently used to produce decellularized scaffolds. As a powerful detergent, SDS can quickly remove cells but at the same time may damage the ECM to a large extent. Triton-100 acts as a more mild detergent and thus better preserves the ECM making this approach more suitable for the development of scaffolds from the liver, pancreas, spleen, kidney, and lung. We adopted $1 \%$ Triton X-100/0.1\% ammonium hydroxide [41] as the perfusate and controlled the perfuse flow rate at a speed of less than $2 \mathrm{~mL} / \mathrm{min}$. After $15 \mathrm{~min}$ of washing with PBS, blood was washed out and the pancreas became white. Following an additional three hours of perfusion using $1 \%$ Triton X$100 / 0.1 \%$ ammonium hydroxide, the pancreas was completely transparent. Increasing the efficiency could reduce the loss of the ECM components and improve the quality of scaffolds. To verify our results, $\mathrm{H} \& \mathrm{E}$ analysis was performed and revealed no basic cell nucleus. The dsDNA content was also just $43.96 \pm 4.07 \mathrm{ng} / \mathrm{mg}$. Residual cell components, such as protein, will trigger a host immune response [42]; therefore, less vestigial cells will relieve the host immune rejection 


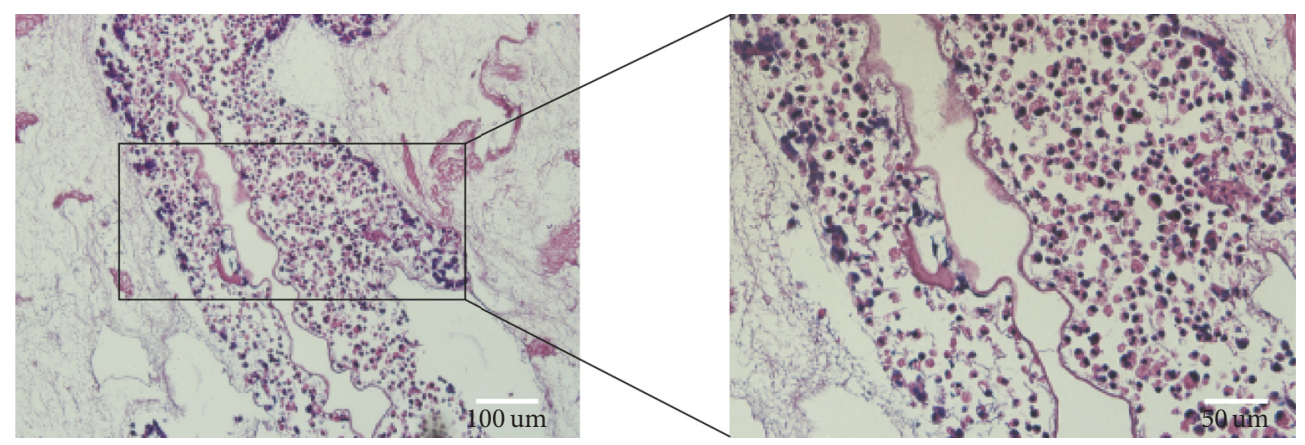

(a)

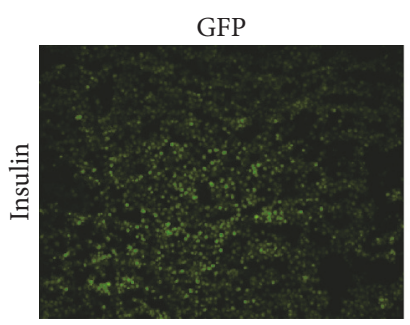

GFP

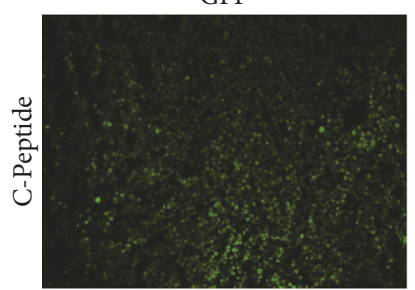

GFP

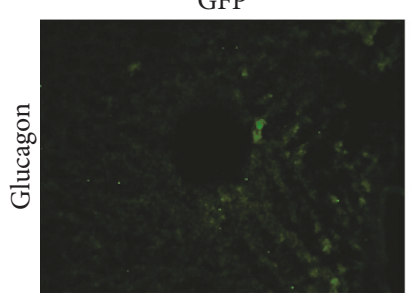

Antibody

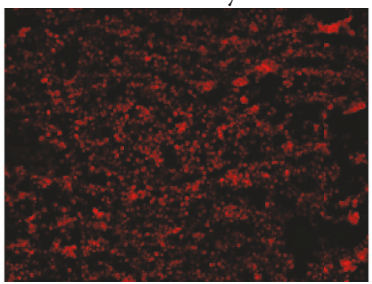

(b)
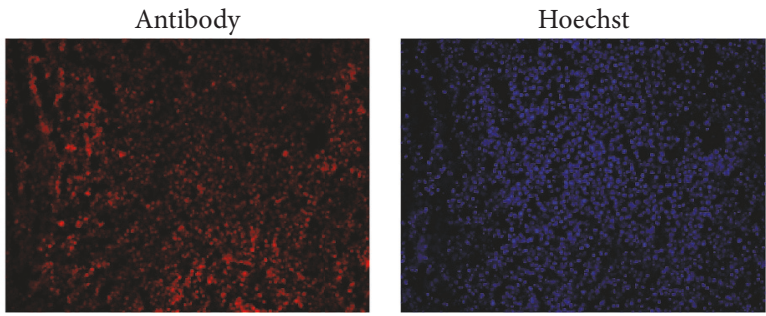

(c)
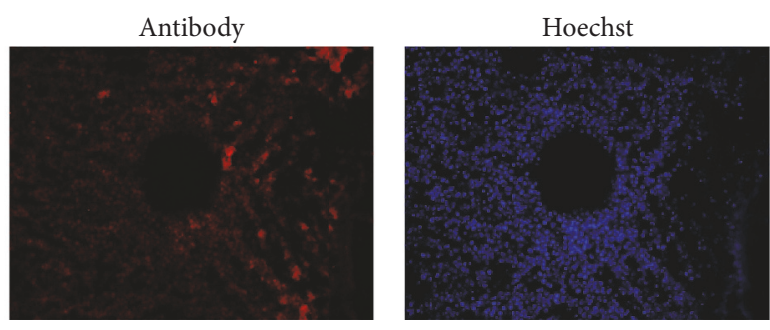

Antibody/Hoechst

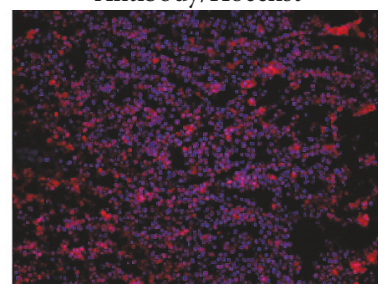

Antibody/Hoechst

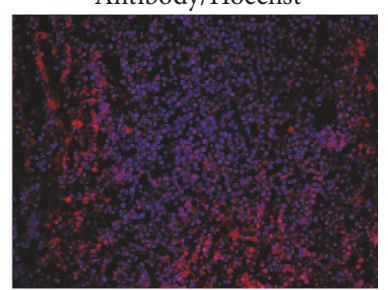

Antibody/Hoechst

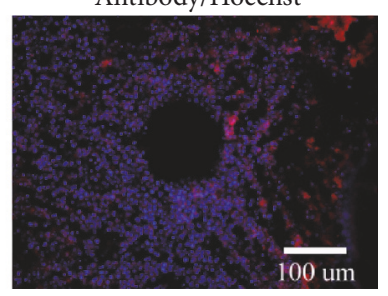

(d)

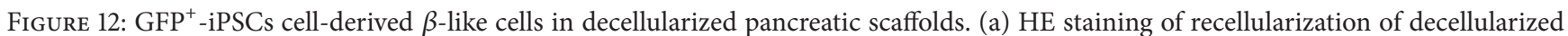
pancreatic scaffolds showed GFP ${ }^{+}$-iPS derived $\beta$-like cells were settled around the vascular lumen. (b, $c$, d) Immunofluorescence demonstrated positivity for insulin, C-peptide, and glucagon thus demonstrating that engrafted cells could survive and function in the scaffolds.

and improve the biocompatibility. In our xenotransplantation experiment, we confirmed the decellularized pancreatic scaffolds as biocompatible. The specimens were examined by HE staining, for up to 21 days after operation. We observed early inflammatory infiltrates on day 3 , reaching their peak on day 7 , after which point the response began to diminish. Notably, the host response was significantly reduced by day 21. At the same time, the pancreatic scaffold structures were well preserved, confirming that the method we adopted was effective and safe. Protein and polysaccharide in the ECM are essential to reconstruct and restore the organization. Immunofluorescence demonstrated that collagen I, collagen
IV, fibronectin, and laminin were well preserved. The GAG content in the decellularized pancreas scaffolds was $70 \%$, compared to the normal pancreas.

Our preliminary work has revealed that 3D decellularized scaffolds of islets performed better than the 2D cultures $[18,19]$. Considering specific ECM should be more suitable for the growth of original cells $[43,44]$. We hypothesized that decellularized pancreatic scaffolds should represent a superior platform to support $\beta$-like cells growth and may provide an alternative source of donor organs. After $\mathrm{GFP}^{+}$iPSCs derived pancreatic $\beta$-like cells were transplanted into scaffolds, the scaffolds were connected to our circle culture 


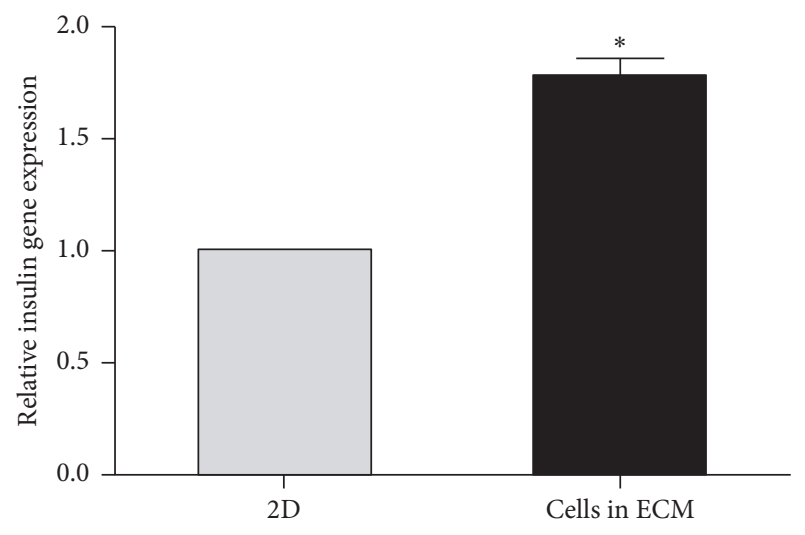

FIGURE 13: Relative insulin gene expression in 2D compared to 3D. Relative insulin gene expression in 3D cultured in the pancreatic scaffold was significantly higher than that of the $2 \mathrm{D}\left({ }^{*} p<0.05\right)$.

system via splenic artery. Continuously nutrient solution and oxygen were perfused into the scaffolds to support cell growth as in vivo. IF confirmed the presence of insulin, C-peptide, and glucagon from our $\mathrm{GFP}^{+}$-iPSCs derived $\beta$-like cells. Moreover, there was a significant increase in the expression of insulin as compared to traditional 2D culture. Taken together, our results allow us to conclude that the $3 \mathrm{D}$ decellularized bioscaffold is a promising material to promote cell growth in vivo.

In our study, we evaluated the idea that $\mathrm{GFP}^{+}$-iPSCs derived pancreatic $\beta$-like cells were well grown and functional in the decellularized pancreatic scaffolds. This makes it possible to evaluate iPSCs derived cells in vitro as in vivo, enhancing our abilities to apply these techniques to various modalities of research such as disease pathology, drug screening, and cell transplantation therapy. The application of stem cell and decellularized scaffolds represents an extremely promising step forward in the search for a cure for diabetes. However, cultivating iPSCs derived pancreatic $\beta$-like cells using decellularized pancreatic scaffolds will be the preliminary work and there is still a long road ahead before the applications of this methodology in clinical practice. Namely, if iPSCs derived pancreatic $\beta$-like cells are to be differentiated and cultured in the scaffolds, it would be significant to explore what growth factors are left after decellularization, since it may affect directly the survival and differentiation of pancreatic $\beta$-like cells. Secondly, our research demonstrated that transplanted cells did not distribute uniformly, although vascular perfusion and multipositional parenchymal injection were taken simultaneously. Also revascularization remains a major bottleneck towards biological engineering, and while we have promising preliminary data towards addressing this issue, more works still need to be performed in future studies [45].

\section{Conclusion}

Our research reveals that the iPSCs will play a crucial role in the regenerative medicine and tissue engineering. On account of deriving from host somatic cells, it will solve those problems such as lack of cell sources and immunological rejection. With selective differentiation medium, it is feasible to obtain the pancreatic $\beta$-like cells. Since it is easy and effective to generate decellularized pancreatic scaffolds nowadays, utilizing the whole organ acellular pancreatic scaffolds will help us explore the cell-ECM interactions in vitro as in vivo, making a novel method to optimize the $\beta$-like cells. In the further, there is more needed to be done such as analyzing mechanisms of differentiation in the decellularized scaffolds. Also, exploring the methods to recellularize the decellularized pancreatic scaffolds with $\beta$-like cells will be a breakthrough in the treatment of diabetes mellitus.

\section{Competing Interests}

The authors declare no competing interests regarding the publication of this paper.

\section{Authors' Contributions}

Jian Wan and Zhiwei Wang contributed to the concept/design. Jian Wan and Pengcheng Zhou contributed to data analysis/interpretation. Jian Wan contributed to drafting the article. Yibing Guo and Shajun Zhu performed the critical revision of article. Zhiwei Wang and Yuhua Lu approved the article. Yan Huang, Cen Wu, and Yao Wang contributed to the statistics. Zhiwei Wang and Yuhua Lu contributed to securing funding. Jian Wan, Lei Wang contributed to data collection.

\section{Acknowledgments}

This research was supported by grants from National Natural Science Foundation of China (nos. 81471801, 81672903) and Medical Innovation Team Program of Jiangsu Province, Science and Technology Project of Nantong City (MS12015017). Mouse $\mathrm{GFP}^{+}$-iPSCs were kindly provided by Stem Cell Bank, Chinese Academy of Sciences.

\section{References}

[1] O. Veiseh, B. C. Tang, K. A. Whitehead, D. G. Anderson, and R. Langer, "Managing diabetes with nanomedicine: challenges and opportunities," Nature Reviews Drug Discovery, vol. 14, no. 1, pp. 45-57, 2014.

[2] J. C. Pickup, "Insulin-pump therapy for type 1 diabetes mellitus," The New England Journal of Medicine, vol. 366, no. 17, pp. 16161624, 2012.

[3] W. Truong, J. R. T. Lakey, E. A. Ryan, and A. M. J. Shapiro, "Clinical islet transplantation at the University of Alberta-the Edmonton experience," Clinical Transplants, pp. 153-172, 2005.

[4] A. J. Ahearn, J. R. Parekh, and A. M. Posselt, "Islet transplantation for Type 1 diabetes: where are we now?” Expert Review of Clinical Immunology, vol. 11, no. 1, pp. 59-68, 2015.

[5] R. P. Robertson, "Islet transplantation as a treatment for diabetes-a work in progress," The New England Journal of Medicine, vol. 350, no. 7, pp. 694-705, 2004.

[6] D. Zhang, W. Jiang, M. Liu et al., "Highly efficient differentiation of human ES cells and iPS cells into mature pancreatic insulinproducing cells," Cell Research, vol. 19, no. 4, pp. 429-438, 2009. 
[7] A. Rezania, J. E. Bruin, P. Arora et al., "Reversal of diabetes with insulin-producing cells derived in vitro from human pluripotent stem cells," Nature Biotechnology, vol. 32, no. 11, pp. 1121-1133, 2014.

[8] R. F. El-Demerdash, L. N. Hammad, M. M. Kamal, and H. O. El Mesallamy, "A comparison of Wharton's jelly and cord blood as a source of mesenchymal stem cells for diabetes cell therapy," Regenerative Medicine, vol. 10, no. 7, pp. 841-855, 2015.

[9] Z. Alipio, W. Liao, E. J. Roemer et al., "Reversal of hyperglycemia in diabetic mouse models using induced-pluripotent stem (iPS)-derived pancreatic $\beta$-like cells," Proceedings of the National Academy of Sciences of the United States of America, vol. 107, no. 30, pp. 13426-13431, 2010.

[10] B. Nilsson, K. N. Ekdahl, and O. Korsgren, "Control of instant blood-mediated inflammatory reaction to improve islets of Langerhans engraftment," Current Opinion in Organ Transplantation, vol. 16, no. 6, pp. 620-626, 2011.

[11] B. Oberwallner, A. Brodarac, Y.-H. Choi et al., "Preparation of cardiac extracellular matrix scaffolds by decellularization of human myocardium," Journal of Biomedical Materials Research - Part A, vol. 102, no. 9, pp. 3263-3272, 2014.

[12] T.-Y. Lu, B. Lin, J. Kim et al., "Repopulation of decellularized mouse heart with human induced pluripotent stem cell-derived cardiovascular progenitor cells," Nature Communications, vol. 4, article no. 2307, 2013.

[13] M. Ghaedi, E. A. Calle, J. J. Mendez et al., "Human iPS cell-derived alveolar epithelium repopulates lung extracellular matrix," The Journal of Clinical Investigation, vol. 123, no. 11, pp. 4950-4962, 2013.

[14] B. E. Uygun, A. Soto-Gutierrez, H. Yagi et al., "Organ reengineering through development of a transplantable recellularized liver graft using decellularized liver matrix," Nature Medicine, vol. 16, no. 7, pp. 814-820, 2010.

[15] R. Lang, M. M. Stern, L. Smith et al., "Three-dimensional culture of hepatocytes on porcine liver tissue-derived extracellular matrix," Biomaterials, vol. 32, no. 29, pp. 7042-7052, 2011.

[16] J. J. Song, J. P. Guyette, S. E. Gilpin, G. Gonzalez, J. P. Vacanti, and H. C. Ott, "Regeneration and experimental orthotopic transplantation of a bioengineered kidney," Nature Medicine, vol. 19, no. 5, pp. 646-651, 2013.

[17] S.-K. Goh, S. Bertera, P. Olsen et al., "Perfusion-decellularized pancreas as a natural 3D scaffold for pancreatic tissue and whole organ engineering," Biomaterials, vol. 34, no. 28, pp. 6760-6772, 2013.

[18] P. Zhou, Y. Guo, Y. Huang et al., "The dynamic three-dimensional culture of islet-like clusters in decellularized liver scaffolds," Cell and Tissue Research, vol. 365, no. 1, pp. 157-171, 2016.

[19] T. Xu, M. Zhu, Y. Guo et al., "Three-dimensional culture of mouse pancreatic islet on a liver-derived perfusion-decellularized bioscaffold for potential clinical application," Journal of Biomaterials Applications, vol. 30, no. 4, pp. 379-387, 2015.

[20] J. Jiang, W. Lv, X. Ye et al., "Zscan4 promotes genomic stability during reprogramming and dramatically improves the quality of iPS cells as demonstrated by tetraploid complementation," Cell Research, vol. 23, no. 1, pp. 92-106, 2013.

[21] K. P. Smith, M. X. Luong, and G. S. Stein, "Pluripotency: toward a gold standard for human ES and iPS cells," Journal of Cellular Physiology, vol. 220, no. 1, pp. 21-29, 2009.

[22] I. S. Schroeder, A. Rolletschek, P. Blyszczuk, G. Kania, and A. M. Wobus, "Differentiation of mouse embryonic stem cells to insulin-producing cells," Nature Protocols, vol. 1, no. 2, pp. 495507, 2006.
[23] T. Kobayashi, T. Yamaguchi, S. Hamanaka et al., "Generation of rat pancreas in mouse by interspecific blastocyst injection of pluripotent stem cells," Cell, vol. 142, no. 5, pp. 787-799, 2010.

[24] K. Takahashi and S. Yamanaka, "Induction of pluripotent stem cells from mouse embryonic and adult fibroblast cultures by defined factors," Cell, vol. 126, no. 4, pp. 663-676, 2006.

[25] A. Rakovic, P. Seibler, and C. Klein, "IPS models of Parkin and PINK1," Biochemical Society Transactions, vol. 43, pp. 303-307, 2015.

[26] I. de Lázaro, A. Yilmazer, and K. Kostarelos, "Induced pluripotent stem (iPS) cells: a new source for cell-based therapeutics?" Journal of Controlled Release, vol. 185, no. 1, pp. 37-44, 2014.

[27] M. T. Lam and M. T. Longaker, "Comparison of several attachment methods for human iPS, embryonic and adiposederived stem cells for tissue engineering," Journal of Tissue Engineering and Regenerative Medicine, vol. 6, supplement 3, pp. s80-s86, 2012.

[28] A. M. Martins, G. Vunjak-Novakovic, and R. L. Reis, "The current status of iPS cells in cardiac research and their potential for tissue engineering and regenerative medicine," Stem Cell Reviews and Reports, vol. 10, no. 2, pp. 177-190, 2014.

[29] L. Wang, Y. Huang, Q. Guo et al., "Differentiation of iPSCs into insulin-producing cells via adenoviral transfection of PDX-1, NeuroD1 and MafA," Diabetes Research and Clinical Practice, vol. 104, no. 3, pp. 383-392, 2014.

[30] L. Wang, M. Zhu, Q. Guo et al., "Comparing the reprogramming efficiency of mouse embryonic fibroblasts, mouse bone marrow mesenchymal stem cells and bone marrow mononuclear cells to iPSCs," In Vitro Cellular and Developmental Biology - Animal, vol. 48, no. 4, pp. 236-243, 2012.

[31] X. Li, Z.-Y. Shan, Y.-S. Wu et al., "Generation of neural progenitors from induced Bama miniature pig pluripotent cells," Reproduction, vol. 147, no. 1, pp. 65-72, 2014.

[32] D. K. Singla, X. Long, C. Glass, R. D. Singla, and B. Yan, "Induced pluripotent stem (iPS) cells repair and regenerate infarcted myocardium," Molecular Pharmaceutics, vol. 8, no. 5, pp. 1573-1581, 2011.

[33] G. Amabile, R. S. Welner, C. Nombela-Arrieta et al., "In vivo generation of transplantable human hematopoietic cells from induced pluripotent stem cells," Blood, vol. 121, no. 8, pp. 12551264, 2013.

[34] A. Soejitno and P. K. A. Prayudi, "The prospect of induced pluripotent stem cells for diabetes mellitus treatment," Therapeutic Advances in Endocrinology and Metabolism, vol. 2, no. 5, pp. 197-210, 2011.

[35] H. Kaneto, T. Miyatsuka, T. Shiraiwa et al., "Crucial role of PDX1 in pancreas development, $\beta$-cell differentiation, and induction of surrogate $\beta$-cells," Current Medicinal Chemistry, vol. 14, no. 16, pp. 1745-1752, 2007.

[36] B. N. Ediger, A. Du, J. Liu et al., "Islet-1 is essential for pancreatic $\beta$-cell function," Diabetes, vol. 63, no. 12, pp. 4206-4217, 2014.

[37] B. Taylor, F.-F. Liu, and M. Sander, "Nkx6.1 is essential for maintaining the functional state of pancreatic beta cells," Cell Reports, vol. 4, no. 6, pp. 1262-1275, 2013.

[38] L. Wilding and M. Gannon, "The role of pdx1 and HNF6 in proliferation and differentiation of endocrine precursors," Diabetes/Metabolism Research and Reviews, vol. 20, no. 2, pp. 114-123, 2004.

[39] R. C. Sartore, P. B. Campos, C. A. Trujillo et al., "Retinoic acidtreated pluripotent stem cells undergoing neurogenesis present increased aneuploidy and micronuclei formation," PLOS ONE, vol. 6, no. 6, Article ID e20667, 2011. 
[40] V. R. Haas, A. R. Santos Jr., and M. L. F. Wada, "Behaviour of fibroblastic cells cultured in collagen I using the sandwich technique," Cytobios, vol. 413, supplement 2, pp. 255-267, 2001.

[41] P. M. Baptista, M. M. Siddiqui, G. Lozier, S. R. Rodriguez, A. Atala, and S. Soker, "The use of whole organ decellularization for the generation of a vascularized liver organoid," Hepatology, vol. 53, no. 2, pp. 604-617, 2011.

[42] T. J. Keane, R. Londono, N. J. Turner, and S. F. Badylak, "Consequences of ineffective decellularization of biologic scaffolds on the host response," Biomaterials, vol. 33, no. 6, pp. 1771-1781, 2012.

[43] A. B. Daly, J. M. Wallis, Z. D. Borg et al., "Initial binding and recellularization of decellularized mouse lung scaffolds with bone marrow-derived mesenchymal stromal cells," Tissue Engineering Part A, vol. 18, no. 1-2, pp. 1-16, 2012.

[44] J. E. Frith, R. J. Mills, J. E. Hudson, and J. J. Cooper-White, "Tailored integrin-extracellular matrix interactions to direct human mesenchymal stem cell differentiation," Stem Cells and Development, vol. 21, no. 13, pp. 2442-2456, 2012.

[45] P. Zhou, Y. Huang, Y. Guo et al., "Decellularization and recellularization of rat livers with hepatocytes and endothelial progenitor cells," Artificial Organs, vol. 40, no. 3, pp. E25-E38, 2016. 


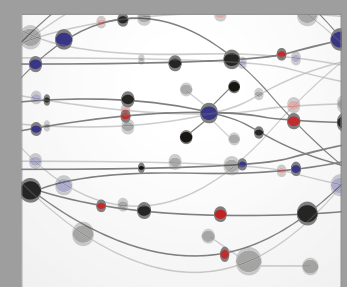

The Scientific World Journal
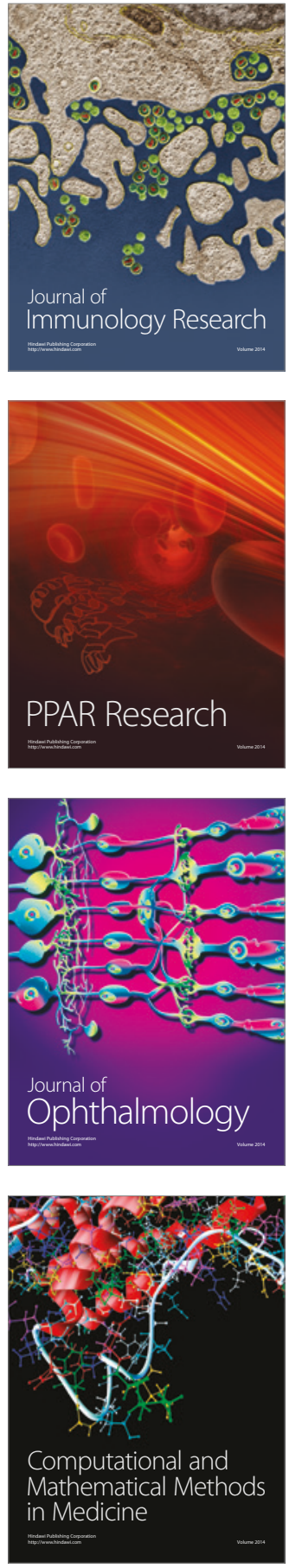

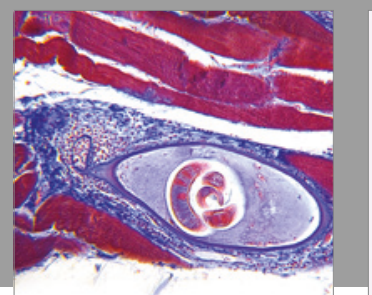

Gastroenterology Research and Practice
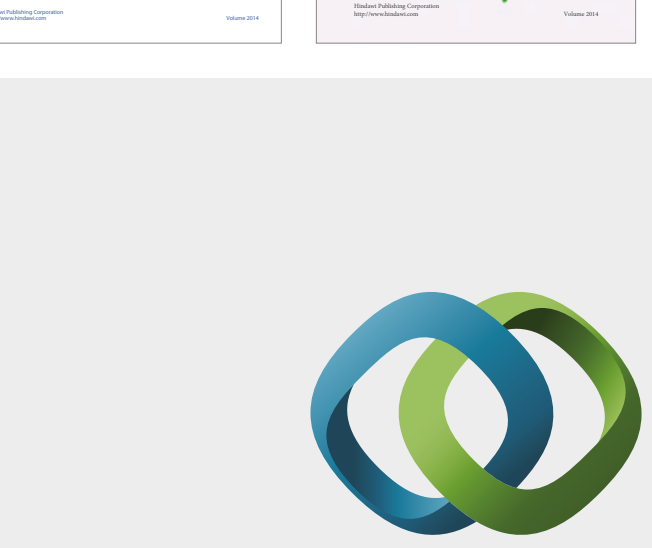

\section{Hindawi}

Submit your manuscripts at

https://www.hindawi.com
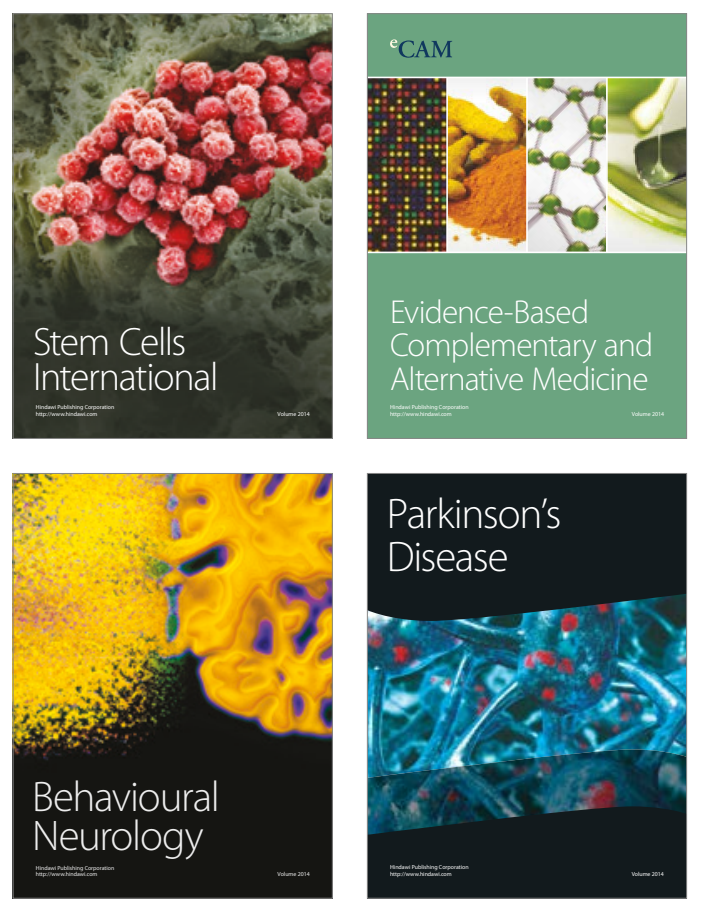
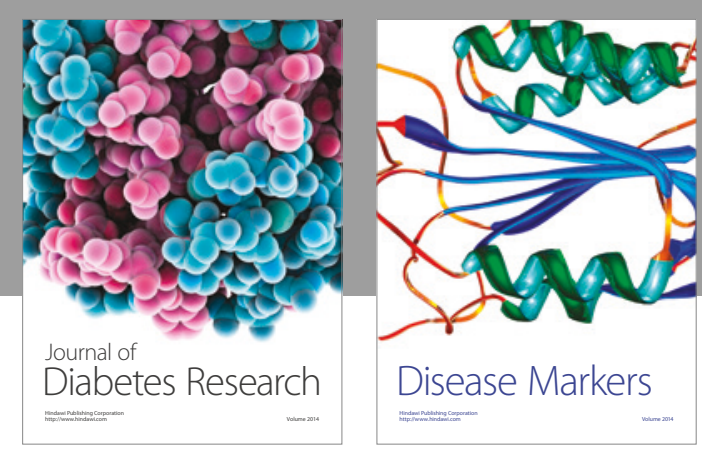

Disease Markers
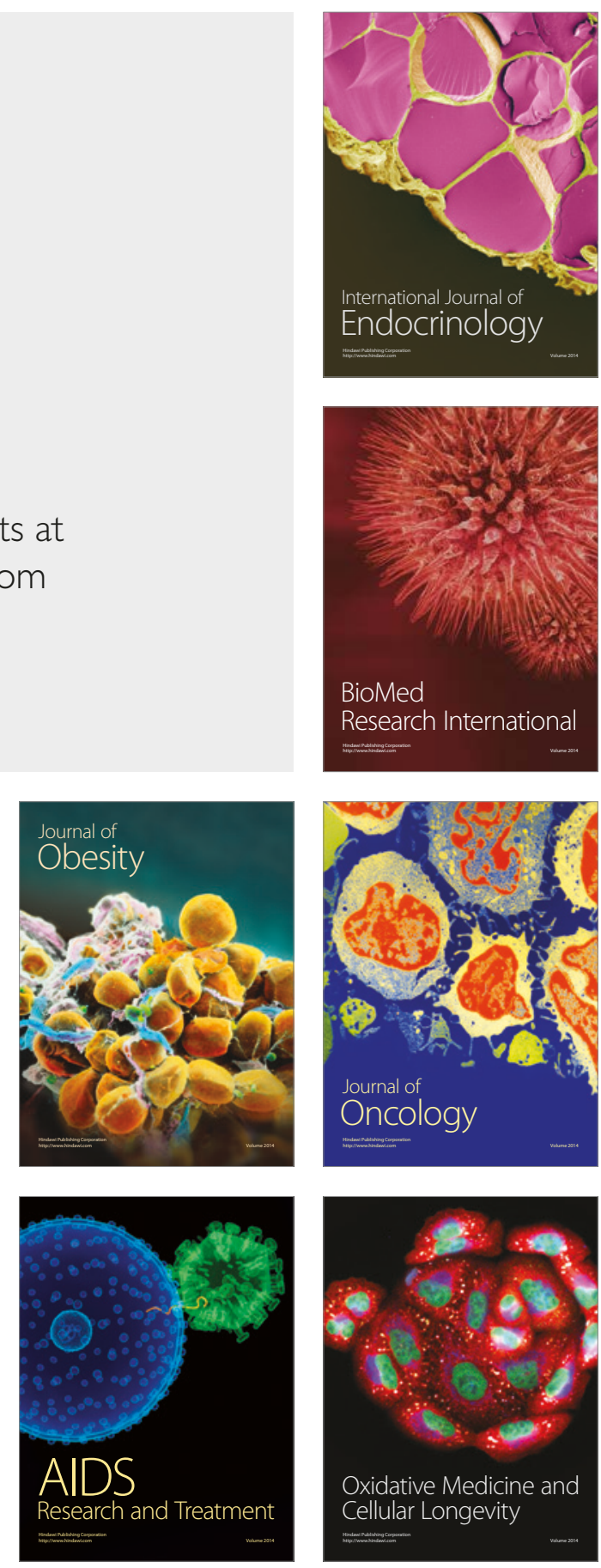